\title{
HOGARES Y CASERÍOS EN LA NAVARRA CANTÁBRICA EN EL SIGLO XIX. UN ENFOQUE MICROANALÍTICO ${ }^{1}$
}

por

\author{
PILAR ERDoZÁIN AZPILICUETA \\ Universidad de Zaragoza
}

Fernando Mikelarena Peña

Universidad de Zaragoza

JuAn IgNaCio Paul ARZaK

IES Lekarotz

RESUMEN: El objetivo de este artículo es analizar las estructuras familiares, el tamaño y la composición de los hogares, así como la relación existente en ellos entre miembros productores y miembros consumidores, entre 1824 y 1894 en dos barrios rurales (Alcayaga y Zalain) de un municipio (Lesaca) situado en la Navarra cantábrica. Se emplea una doble perspectiva, estática y dinámica, analizándose sincrónica $y$ diacrónicamente las informaciones de diez padrones nominales consecutivos.

PALABRAS ClaVE: Historia de la familia. Caserío. Estructuras familiares. Economías familiares. Familia troncal. País Vasco.

ABSTRACT: The object of this article is to analyze the family structures, the size and the composition of the bousebolds, as well as the existent relationship in them between producing members and consumers members, in 1824-1894 in two rural neigbborboods of a municipality of the northwest of Navarra. It is used a double perpective, static and dynamics, being analysed the informations of ten serial nominal censuses.

KEY WORDS: Family History. Family structures. Family economies. Stem family. Basque country.

1 Esta investigación se ha realizado gracias a una ayuda concedida por la sección de Historia de Eusko Ikaskuntza/Sociedad de Estudios Vascos durante los años 1998 y 1999. Asimismo, queremos agradecer las críticas aportadas por los evaluadores anónimos que han ayudado a mejorar este trabajo.

Hispania, LXIII/1, núm. 213 (2003) 199-230 


\section{INTRODUCCIÓN}

Este artículo gira en torno a la familia y el caserío, dos elementos estrechamente entrelazados por cuanto las explotaciones agrarias de los caseríos tenían un marcado carácter familiar. Ese binomio ha recibido una gran atención en la última década. Gracias a diversas contribuciones ${ }^{2}$, nuestro conocimiento de las características del caserío vasco, definible como el conjunto de edificios, tierras, bosques y ganados que servían de infraestructura para la constitución de cada explotación agraria familiar en la Vasconia holohúmeda, así como de nicho ecológico de acogida para los grupos domésticos de esa zona, es hoy en día bastante satisfactorio.

En este artículo analizamos dos aspectos todavía no trabajados en el contexto temático de la familia y el caserío.

De un lado, estudiamos las estructuras familiares y el tamaño y composición de los hogares en el largo plazo desde una perspectiva dinámica que complementa el tradicional enfoque estático seguido en los trabajos anteriormente mencionados, la mayoría de las veces circunscrito a un solo corte cronológico. De esta forma, analizamos sincrónica y diacrónicamente las informaciones que diez padrones nominales del periodo 1824-1894 proporcionan para dos barrios rurales (Alcayaga y Zalain) de un municipio (Lesaca) situado en la Navarra cantábrica. Subrayaremos que el análisis dinámico y diacrónico posibilita percibir todas las interioridades de los grupos familiares, tal y como ha sido puesto de manifiesto por diversos autores 3 .

De otro lado, efectuamos una aproximación a la cuestión de la relación entre miembros productores y miembros consumidores en el seno de los hogares a lo largo del tiempo. Como es sabido, a diferencia de lo que ocurre en el análisis de las economías familiares de contextos de economía industrial y asalariada, donde se cuenta con las nóminas de los establecimientos fabriles, lo que permite concretar los ingresos monetarizados de los hogares ${ }^{4}$, en el caso del análisis centrado en las economías familiares campesinas ${ }^{5}$ es imposible ir más

2 CRuz Mundet, Jose Ramón, Rentería en la crisis del Antiguo Régimen (1750-1845). Familia, caserío y sociedad rural, Rentería, 1991; URRUTIKOETXEA LIZARRAGA, José, "En una casa y compañía». Caserío y familia campesina en la crisis de la sociedad tradicional. Irún, 1766-1845, San Sebastián, 1992; ARBAIZA Villalonga, Mercedes, Familia, trabajo y reproducción social. Una perspectiva microbistórica de la sociedad vizcaina a finales del Antiguo Régimen, Bilbao, 1996.

3 REHER, David-Sven, «La importancia del análisis dinámico ante el análisis estático del hogar y la familia. Algunos ejemplos de la ciudad de Cuenca en el siglo XIX» Revista Española de Investigaciones Sociológicas, $n^{\circ}$ 27, 1984, pp. 107-135; FAUVE-CHAMOUX, Antoinette, "Les structures familiales au royaume des familles souches: Esparros» Annales ESC, 1984, 3, pp. 513-528.

4 PÉreZ-Fuentes Fernández, Pilar, Vivir y morir en las minas, Bilbao, 1993; Camps CurA, Enriqueta, La formación del mercado de trabajo industrial en la Cataluña del siglo XIX, Madrid, 1995.

5 REHER, David-Sven, Familia, población y sociedad en la provincia de Cuenca, 1700-1970, Madrid, 1988; ERdozÁin, Pilar y MikelarenA, Fernando, «Economías familiares campesinas en Navarra. Primeros resultados» en Fernández PrIeto, Lourenzo y BALBOA, Xésus, eds., La sociedad 
allá del cociente entre unidades de trabajo y unidades de consumo por ser incognoscibles, a causa de no haber fuentes documentales para ello, las labores, en gran medida de naturaleza pluriactiva, a las que se dedicaba en la práctica la mano de obra potencial presente en las unidades familiares, así como el grado de remuneración de las mismas y la estructura de gastos totales (no sólo los de alimentación) de los grupos domésticos. Ahora bien, a pesar de que la concreción del cociente entre miembros productores y miembros consumidores en los hogares sea el objetivo límite al que se pueda aspirar en la investigación acerca de las economías familiares campesinas, ahondar en ello no es algo insustancial. Ya Chayanov ${ }^{6}$ destacó que el grado de autoexplotación de las unidades familiares y el volumen de actividad económica global de las mismas dependía de los valores de aquel cociente, cambiantes según el ciclo de vida. Relacionado con todo esto, el interrogante en el que profundizaremos es el de si los hogares de los campesinos de los barrios estudiados, fundamentados mayoritariamente en las pautas propias de la familia troncal, un tipo de familia dotado teóricamente de una elevada elasticidad en relación con el grado de adecuación del volumen de fuerza de trabajo intrafamiliar a las necesidades productivas a causa de las posibilidades que abría el poder contar o no con la aportación y la presencia de parientes corresidentes solteros, lograban mantener por esa vía en todo momento del ciclo de vida de la familia una relación equilibrada entre miembros consumidores y miembros productores.

La documentación de la que nos servimos primordialmente son un catastro de 1844 y diez censos o padrones nominales del período 1824-1894 que se corresponden con los siguientes años: 1824, 1832, 1841, 1850, 1860, 1867, $1871,1880,1886$ y 1894.

El catastro de $1844^{7}$ se habría elaborado en virtud de las instrucciones de formación de los catastros locales ideadas por Yanguas y Miranda, secretario de la Diputación de Navarra ${ }^{8}$. El catastro contiene información sobre los patrimonios y también, lo que constituye una singularidad, sobre explotaciones, consignando los nombres y apellidos de sus titulares, así como el nombre de la casa en la que residían. Por consiguiente, a diferencia de los catastros y amillaramientos de finales del siglo XIX, así como de los del siglo XX, que sólo facilitan datos de propiedades, con este catastro podemos reconstruir unidades de propiedad y unidades de explotación, éstas últimas tanto de propietarios como de arrendatarios.

Los diez censos y padrones nominales que hemos trabajado también se encuentran entre los fondos del Archivo Municipal de Lesaca9 ${ }^{9}$. Todos cuentan

\footnotetext{
rural en la España contemporánea. Mercado y patrimonio, Santiago, 1996, pp. 63-86; ERDOZAIN AZPILICUETA, Pilar, Propiedad, familia y trabajo en la Navarra contemporánea, Pamplona, 1999.

6 Chayanov, A. V., La organización de la unidad económica campesina, Buenos Aires, 1974.

7 Archivo Municipal de Lesaca, cajas 582 y 583.

8 LANA BERASÁIN, J.M., Estadísticas históricas de Navarra. El sector agrario navarro (17851935). Cultivo, ganadería, propiedad y mercados, Pamplona, 1999, p. 47

9 Concretamente en las cajas 104, 105, 106 y 108.
} 
con informaciones sobre el nombre y los apellidos de los individuos (sólo un apellido hasta 1860 y los dos a partir de esa fecha), así como su sexo, edad y estado civil. Otros tipos de informaciones (origen, el nivel de alfabetización) solamente figuran en algunos. Asimismo, las informaciones sobre las ocupaciones son de una calidad dispar, sobresaliendo en este sentido de forma muy destacada el padrón de 1824 y el censo de 1860 . Por otra parte, metodológicamente, de los censos y padrones nominales trabajados no se suscita ningún problema en cuanto que el concepto de hogar manejado en esas listas de habitantes coincide con el empleado actualmente por los científicos sociales ${ }^{10}$. De hecho, en un auto municipal de 19 de diciembre de 1852, presente en el Libro de Actas de 18411858 del ayuntamiento de Lesaca, localidad en la que se enclavaban los barrios que estamos estudiando, se explicaba que en el padrón "van comprendidos bajo un fuego los donadores, donatarios y celivatos, que componiendo una sola familia, comen en una mesa, pagan todos una misma contribución, y viven en una cocina o bajo un bogar» ${ }^{11}$.

Otro cuestión importante es la referente a los nombres de los caseríos que constituyen un elemento de gran ayuda a la hora de emprender reconstrucciones dinámicas de familias como las que en este artículo se han efectuado, en la medida en que facilitan el rastreo de aquellas familias que residen a lo largo del período en una misma casa. Al hilo de esto, tenemos que recordar que, al igual que en todo el entorno vascoparlante, cada casa tenía un nombre que ha permanecido invariado desde mediados del siglo XVII. Pues bien, los censos y padrones nominales utilizados adjuntan el nombre del caserío que habitaba cada familia sólo hasta 1860. Los nombres de los caseríos a partir de 1867 los hemos deducido a partir de las matrículas anuales de feligreses del período 1856-1886 que se encuentran en el Archivo Parroquial de Vera y que son de una utilidad limitada a todos los efectos porque únicamente informan de los nombres y primer apellido de las personas que habitaban en cada casa. La falta de una matrícula tal para deducir el nombre de los caseríos en el censo nominal de 1894 nos ha impedido desarrollar esa operación identificativa para tal fecha, si bien, tal y como se verá en el apartado referido al análisis de la familia desde una perspectiva dinámica, hemos podido identificar muchos caseríos en los que habitaban las respectivas familias reconstruídas a lo largo del tiempo, especialmente las de campesinos propietarios

10 Hay que tener en cuenta que, según indicó Mikelarena en un trabajo publicado en el año 1992, en los censos oficiales españoles a partir de 1877, en virtud de las instrucciones que les acompañaban, los hogares complejos en los que corresidían dos núcleos conyugales subsistentes o rotos se subdividieron en tantos hogares como núcleos conyugales hubieran. MikelarenA PeÑA, F., "Las estructuras familiares en la España tradicional: geografía y análisis a partir del censo de 1860", Boletín de la $A D E H, \mathrm{X}-3,1992$, pp. 16-20. Ese sesgo no empaña nuestra investigación porque las listas nominales de habitantes que hemos empleado para 1867, 1871, 1880, 1886 y 1894 son, en todos los casos, padrones.

11 Archivo Municipal de Lesaca, Libro de Actas 1841-1858, sin foliar.

Hispania, LXIII/1, núm. 213 (2003) 199-230 


\section{LA SITUACIÓN GEOGRÁFICA DE LOS BARRIOS ESTUDIADOS}

Los barrios de Alcayaga y de Zalain pertenecen al municipio de Lesaca, situándose en su extremo nororiental, lindando por el norte con el curso del río Bidasoa, por el sur con los montes de Baldrún y Otsango, que los separan del resto de la localidad, y por el oeste con las estribaciones del macizo de Peñas de Aya, en cuya otra vertiente se encuentran Irún y Oyarzun.

La comarca de Cinco Villas en la que se inscribe el municipio de Lesaca del que dependen los dos barrios de Alcayaga y Zalain se caracteriza, como consecuencia de la fuerte acción erosiva, por ser un terreno accidentado de bajas altitudes. Respecto al clima, a las características climáticas propias de la Vasconia cantábrica hay que añadir que la cercanía del Cantábrico (distante de los barrios de Alcayaga y Zalain en línea recta solamente a unos 7 kilómetros), contribuía a suavizar el clima y a caracterizarlo por una fuerte humedad. Asimismo, la escasa altitud de las vegas conllevaba que los fríos no fueran muy intensos. Acerca de la altitud, la mayor parte de los caseríos de Alcayaga y Zalain se encuentran situados a orillas prácticamente del Bidasoa y por tanto también se ubican a cotas inferiores a los 50 metros, con la sola excepción de unos pocos caseríos del primer barrio (Matxienea, Borda, Soroa e Iparragirrea) situados todo lo más una decena de metros más arriba y de los caseríos de $\mathrm{Za}$ lain Errotaldekoborda, Etxeberrikoborda y Majirenarenborda situados entre los 75 y los 100 metros al lado del sendero que unía ese barrio con el casco de Lesaca. Así pues, nos encontramos ante un clima atlántico, sin grandes oscilaciones térmicas, con temperaturas moderadas, de inviernos suaves con pocas heladas y con veranos templados, en el que la humedad es intensa y constante y las precipitaciones sumamente frecuentes. De hecho, la pluviosidad se sitúa en torno a los $1.500 \mathrm{~mm}$., siendo los días con lluvia entre 165 y 170 .

Por efecto de tal clima, el paisaje vegetal se caracteriza por la existencia y extensión de prados cerca de los caseríos y en el monte que favorecen la dedicación ganadera de los caseríos para compensar los obstáculos a la producción de cereal (en especial hasta el inicio del siglo XVII, cuando se introduzca el cultivo del maíz) y de otras producciones agrícolas como la vitícola.

Los caseríos de los barrios de Alcayaga y Zalain tenían a su disposición para el cultivo las ricas vegas que se extendían hasta el mismo río, vegas actualmente ocupadas por fábricas y polígonos industriales. De hecho, en los catastros de Lesaca de 1811 y 1844 llama la atención el hecho de que los caseríos de esos dos barrios se caractericen, frente a los demás barrios del municipio, por la mucha mayor presencia de tierras de la mejor calidad. En dichas vegas, los caseríos de Alcayaga y Zalain disponían de fértiles terrenos dedicados a cereales (en especial a maíz), a fenerales o pastizales y a manzanales. Asimismo, en los montes situados a sus espaldas disponían de prados de invierno, de castañales y de robledales que les servían para alimentar al ganado y a las personas mismas en el caso de los castañales, así como de helechales que empleaban como cama

Hispania, LXIII/1, núm. 213 (2003) 199-230 
para el ganado estabulado para mezclarlo con sus heces y utilizarlo como abono orgánico. También hay que recalcar que en esos mismos montes los habitantes de esas poblaciones encontraban los recursos naturales ligados al bosque y al subsuelo, fundamentalmente leña para el consumo de su hogar como fuente calorífica o para elaborar carbón vegetal y mineral de hierro para suministrar a las abundantes ferrerías de la zona.

En su conjunto, la población de los dos barrios estuvo constituída durante el periodo 1824-1894 por unas 220-230 personas, agrupadas en una cifra de hogares que osciló entre los 38 y los 45 . El conjunto de los dos barrios mencionados se componía de unos 33 caseríos. El barrio de Alcayaga se componía de trece caseríos: Barrenetxea, Gartzienea, Errandonea, Garaikoetxea, Etxeberria, Martiñenea, Matxienea, Borda, Soroa, Iparragirrea, Mariskonea, Iparragirreberria y Kamaindegi. Todos ellos estuvieron habitados a lo largo de todo el periodo con la excepción de los tres últimos. En Mariskonea no residió nadie hasta los años cincuenta a causa de haber quedado en mal estado por los combates que tuvieron lugar en 1813 entre las tropas aliadas de Wellington y el ejército francés en retirada ${ }^{12}$. Por su parte, Iparragirreberria, si bien se construyó en 1854 en el centro de las tierras de Iparragirrea, empezó habitarse hacia mediados de la década de los sesenta, momento éste en que Rafael Maria de Leguía tomo posesión de ella ${ }^{13}$. Para finalizar, Kamaindegi comenzó a ocuparse a finales de los ochenta.

El barrio de Zalain contaba con 16 caseríos habitados en 1824, sumándoseles otros cuatro más en el curso de los años. Los caseríos de Zalain que en 1824 acogían a gente eran: Berekoetxea, Barrenetxea, Aldategia, Olarenea, Agustinbaita, Bordatxarrea, Telletxea, Landakoetxea o Landa, Bertizbaita, Peritxenea, Iturria, Etxeberria, Errotaldea, Errota, Borda y Mikelperitzenea. Los caseríos que, con los años, pasaron a estar habitados eran: Errotaldekoborda, Etxeberrikoborda, Majirenarenborda y Telletxekoetxeberria. Como se ve, de estos cuatro caseríos, tres de ellos eran bordas habilitadas como caseríos, siendo en dos casos pertenecientes a casas preexistentes en el mismo barrio. Por otra parte, algunos de los caseríos mencionados no estaban habitados en algunas fechas censales: así por ejemplo Bordatxarrea en 1860; Errota en 1860, 1880 y 1886; Errotaldekoborda en 1871 y Telletxekoetxeberria en 1871 y 1886.

El número de unidades familiares que habitaba en los caseríos de los dos barrios varió a lo largo del periodo, alcanzándose las mayores cifras en las fechas centrales: de 38 hogares en 1824 y en 1832 se pasó a 44 en 1841 , a 45 en 1850, a 42 en 1860, a 44 en 1867, a 41 en 1871, a 40 en 1880, a 41 en 1886 y a 40 en 1894 .

12 Archivo General de Navarra, Sección de Protocolos Notariales, Notaría de Lesaca, Escribano J. F. Echenique, legajo 42, año 1828, documento 79.

13 Archivo General de Navarra, Sección de Protocolos Notariales, Notaría de Lesaca, Escribano T. Loyarte, legajo 74, año 1865 , documento 54 
Mientras en algunos caseríos habitaba solamente un grupo doméstico, en otros residían dos, tres, cuatro e incluso cinco, no habiendo continuidad en muchas ocasiones en el número de hogares existente en un mismo caserío en el curso del periodo 1824-1894. De hecho, los únicos caseríos habitados a lo largo de todo el periodo que registran el mismo número de hogares a lo largo de todo el periodo son los 10 siguientes: Soroa, Berekoetxea, Aldategia, Agustinbaita, Landakoetxea, Bertizbaita, Peritxenea, Etxeberria, Errotaldea y Borda de Zalain. A ellos podrían añadírseles otros siete (Mariskonea, Iparragirreberria, Errota, Errotaldekoborda, Etxeberrikoborda, Majirenarenborda y Telletxekoetxeberria) no habitados continuamente en todas las fechas censales que tomamos como testigos, pero en los que en los momentos en que contenían a hogares en su interior siempre existía el mismo número de éstos. En los otros 15 caseríos (esto es, algo más de la mitad de la cifra total de caseríos de los dos barrios que era de 29), se registraron variaciones en cuanto a la cifra de grupos domésticos que los habitaban. Los caseríos que registraban oscilaciones en el número de grupos domésticos que albergaban se localizaban muy mayoritariamente en el barrio de Alcayaga.

No existen relaciones demasiado claras entre el hecho de la persistencia de que un mismo número de grupos domésticos ocupara a lo largo del tiempo un caserío y el hecho de quienes lo habitasen fueran propietarios o arrendatarios. De los 17 caseríos que hemos citado anteriormente en los que siempre se detecta la misma cifra de hogares habitándolos hay 8 casos de caseríos que contenían en 1860 (fecha del único censo que nos informa la clase social a la que pertenecían los grupos domésticos) a sus propietarios (son Aldategia, Landa, Bertizbaita, Peritxenea, Etxeberria, Errotaldea, Borda de Zalain y Telletxekoetxeberria), pero hay 9 (Soroa, Berekoetxea, Agustinbaita, Mariskonea, Iparragirreberria, Errota, Errotaldekoborda, Etxeberrikoborda y Majirenarenborda) en los que en dicha fecha residían renteros. De todo ello solamente puede afirmarse que algunos caseríos estuvieron permanentemente habitados por las familias que era propietarias de los mismos y que otros caseríos que se explotaban a través de contratos de arrendamiento siempre estuvieron ocupados por un hogar de colonos. Asimismo, se puede decir que otros caseríos explotados directamente por sus propietarios en algunos momentos registraron en otros fragmentaciones de su unidad de producción, cediéndose una porción de los mismos a grupos domésticos de arrendatarios. Igualmente, algunos caseríos que en unas fechas fueron gestionados por un determinado número de colonos, en otros momentos soportaron otras cifras de renteros por lo que las dimensiones de las empresas agrarias llevadas a renta contenidas en aquéllos divergieron en el curso de los años.

Acerca del grado de grado de representatividad de estos caseríos en relación con los caseríos de la Vasconia Cantábrica, consideramos que constituyen un universo que reproduce con bastante fidelidad las diferentes situaciones que podían darse (caseríos situados en vegas, caseríos situados en laderas de monte, 
caseríos explotados directamente por propietarios, caseríos explotados por uno o varios grupos domésticos de campesinos arrendatarios). También consideramos que el entorno geográfico y los recursos agropecuarios y pluriactivos con los que contaban estos caseríos serían similares a los de otros grupos de caseríos de la comarca navarra estudiada o de otras comarcas de Guipúzcoa y Vizcaya.

\section{LA ESTRUCTURA SOCIAL DE LOS BARRIOS ESTUDIADOS}

En cuanto a su estructura social, estos dos barrios se dividían en dos sectores sociales: uno formado por campesinos propietarios y otro integrado por campesinos arrendatarios. En el censo nominal de 1860, el mejor censo de cara a cuantificar la presencia de cada sector se contabilizan 18 hogares de campesinos propietarios y 24 de arrendatarios. Es decir, en términos porcentuales, una presencia del 42,8 por ciento de hogares de campesinos propietarios sobre el total de hogares y otra del 57,1 por ciento de hogares de campesinos renteros. El número de los campesinos arrendatarios era proporcionalmente mucho más elevado en Alcayaga que en Zalain: mientras que aquí su número era similar al de campesinos propietarios ( 12 y 11 respectivamente), allí era más alto (13 hogares de inquilinos y 6 de propietarios).

Por otra parte, también hay que poner de relieve que, mientras las familias de campesinos propietarios eran familias que, por lo general, permanecían siempre residiendo en el mismo caserío, entre las familias de campesinos renteros había una gran movilidad geográfica a causa de la expiración de los plazos de arrendamiento y de la no renovación de alquileres, advirtiéndose numerosas entradas y salidas de estas familias de un censo a otro e incluso cambios de residencia de un caserío a otro dentro del espacio físico de estos barrios o dentro de alguno de ellos.

La forma de explotación de los caseríos de estos dos barrios conocía tres variantes: la primera de ellas, la de los caseríos trabajados directamente por sus dueños; la segunda, la de los caseríos en los que la unidad de propiedad se escindía en dos explotaciones, una trabajada por el dueño y otra trabajada por un inquilino; la tercera y.última, la de los caseríos habitados y cultivados solamente por arrendatarios, fuera por uno o por varios grupos domésticos de esta clase social.

Los caseríos explotados de cada una de esas tres maneras no siempre fueron los mismos. Como prueba de ello, cotejaremos las informaciones que, al respecto, nos ofrecen el catastro de 1811 , el catastro de 1844 y el censo de 1860 . El número de caseríos en los que habitaban únicamente los hogares constituídos por sus propietarios era de 13 en 1811, de 17 en 1844 (contando que en los caseríos Olarenea y Mikelperitzenea vivían dos hogares de propietarios en cada uno de ellos) y de 13 en 1860, pero sólo en 8 de ellos (los de Errandonea, Garaikoetxea, Borda, Errotaldea, Bertizbaita, Aldategia, Landa y Peritxenea) contenían sólo a familias propietarias en las tres fechas. En lo que respecta a los 
caseríos habitados solamente por inquilinos eran 12 en 1811 y en 1844 y de ellos sólo en 8 seguían viviendo únicamente arrendatarios en 1860.

Por otra parte, gracias a las informaciones del catastro de 1844 , en los que se detallan los bienes propios de los propietarios, pero también los propios y arrendados de los inquilinos, podemos aproximarnos a las dimensiones de las explotaciones agrarias.

\subsection{Las explotaciones agrarias de los campesinos propietarios}

Según se ve en el Cuadro 1, las explotaciones agrarias de los campesinos propietarios tenían por término medio 1,69 hectáreas de tierra, de las que 1,30 eran de tierra propia dedicada a cereal, 0,25 de pastos y manzanales también propios, 0,08 de tierra no cultivada y 0,06 de tierra alquilada a otro dueño. Por otra parte, las cifras medias de bueyes y vacas por propietario eran de 2,6 y las de ovejas y cabras, de. 25. De cualquier forma, los datos individuales nos siguen informando de que estas explotaciones eran de pequeñas dimensiones: 3 de ellas no llegaban a la hectárea de tierra, 8 estaban entre la hectárea y las dos hectáreas, 7 se situaban entre las dos y las tres hectáreas y solamente una sobrepasaba las tres hectáreas, rozando casi las cuatro. En el ganado las disparidades eran más atenuadas. Interesa subrayar el poco seguimiento que estos propietarios cultivadores directos hacían del arriendo de la tierra: sólo seis de ellos (es decir, menos de un tercio) llevaban parcelas de tierra arrendada de muy pequeñas dimensiones. Por lo tanto, el alquiler de tierra por parte de ese sector poblacional no era una práctica demasiado seguida de cara a maximizar beneficios.

\section{CUADRO 1: EXPLOTACIONES AGRARIAS DE LOS CASERÍOS CULTIVADOS DIRECTAMENTE POR SUS PROPIOS DUEÑOS EN 1844.}

\begin{tabular}{|l|c|c|c|c|c|c|c|c|c|c|c|}
\cline { 2 - 9 } \multicolumn{1}{c|}{} & TC & TMF & TI & TA & TT & CS & VC & LN & CB & CE & AB \\
\hline ALDATEGIA & 1,74 & 0,27 & & & 2,01 & 10 & 2 & & & 1 & \\
1/2 OLARENEA & 0,33 & & & 0,13 & 0,46 & 2 & & & 1 & & \\
1/2 OLARENEA & & & & 0,27 & 0,27 & 20 & 2 & & & & \\
TELLETXEA & 3,22 & & 0,74 & & 3,96 & 30 & 3 & 30 & & 1 & \\
LANDA & 0,80 & 0,13 & & 0,13 & 1,06 & 14 & 3 & 30 & & 1 & \\
BERTIZBAITA & 1,07 & & & & 1,07 & 10 & 3 & 50 & & 1 & \\
PERITXENEA & 1,95 & & & & 1,95 & 30 & 4 & 35 & & 1 & 20 \\
ITURRIA & 1,61 & 0,54 & 0,47 & & 2,62 & 24 & 4 & 80 & & 1 & \\
ETXEBERRIA & 0,13 & 0,87 & & & 1,00 & 30 & 3 & 30 & & 1 & 6 \\
ERROTALDEA & 1,07 & & & & 1,07 & 40 & 3 & 35 & & 1 & \\
MIKELPERITZENEA & 0,80 & 0,13 & & & 0,93 & 10 & 4 & & 1 & 1 & 20 \\
MIKELPERITZENEA & 1,41 & 0,94 & & & 2,35 & 24 & 3 & 26 & & 1 & \\
BORDA & 0,74 & 0,13 & & & 1,14 & 18 & & 15 & 2 & 1 & \\
\hline
\end{tabular}


CUADRO 1: EXPLOTACIONES AGRARIAS DE LOS CASERÍOS CULTIVADOS DIRECTAMENTE POR SUS PROPIOS DUEÑOS EN 1844. (Cont.)

\begin{tabular}{|l|c|c|c|c|c|c|c|c|c|c|c|}
\cline { 2 - 10 } \multicolumn{1}{c|}{} & TC & TMF & TI & TA & TT & CS & VC & LN & CB & CE & AB \\
\hline MATXIENEA & 1,48 & 0,04 & & & 1,52 & 6 & 2 & & & 1 & \\
MARTINENENEA* & 1,34 & 0,87 & & & 2,21 & 10 & 2 & 35 & & 1 & \\
GARAIKOETXEA & 1,74 & 0,40 & & & 2,14 & & 3 & & & 1 & \\
ETXEBERRIA ALK & 1,34 & & & & 1,34 & & 2 & 40 & & & \\
ERRANDONEA & 1,61 & 0,50 & & & 2,11 & 6 & 3 & 40 & & 1 & \\
GARTZIENEA & 2,41 & & 0,27 & 0,27 & 2,95 & 4 & 3 & 30 & & 1 & \\
MEDIA & 1,30 & 0,25 & 0,08 & 0,06 & 1,69 & 15 & 2,6 & 25 & 0,2 & 0,8 & 2,4 \\
\hline
\end{tabular}

* 0,537 hectáreas son de tres hermanos del dueño.

NOTA: TC: HECTÁREAS DE TIERRA PROPIA DEDICADA A CEREAL; TFM: HECTÁREAS DE TIERRA PROPIA DEDICADA A FENERALES Y MANZANALES; TI: HECTÁREAS DE TIERRA PROPIA INCULTA; TA: HECTÁREAS DE TIERRA ARRENDADA; CS: CARGAS DE CASTAÑAS; VC: CABEZAS DE GANADO BOYERAL Y VACUNO; LN: CABEZAS DE GANADO CAPRINO Y LANAR; CB: CABEZAS DE GANADO CABALLAR; CE: CABEZAS DE GANADO CERDIO; AB: NÚMERO DE COLMENAS DE ABEJAS.

FUENTE: CATASTRO DE LESACA DE 1844. ARCHIVO MUNICIPAL DE LESACA. ELABORACIÓN PROPIA.

\subsection{Las explotaciones agrarias de los campesinos arrendatarios}

Si las explotaciones agrarias de los propietarios cultivadores directos contaban, según lo visto con escasa tierra y ganado, los recursos de las explotaciones de los renteros que ocupaban caseríos, solos o en compañía de otros, no podían ser lógicamente demasiado elevados. En el Cuadro 2 figuran las extensiones de tierra que arrendaban y las cabezas de ganado a su cargo en la fecha de 1844 . Como se ve, el volumen de tierra que arrendaban se situaba en torno a la hectárea. Asimismo, era muy común que estos renteros tuvieran 2 ó 3 vacas y algunos pocos llegaban a contar con rebaños de ovejas y cabras. De otra parte, también se puede apreciar que las explotaciones agrarias de los renteros no eran en todos los casos de las mismas dimensiones. Así, por ejemplo, dos arrendatarios del caserío Barrenetxea de Alcayaga en 1844 (que manejaban superficies de cultivo superiores a las que trabajaban muchos campesinos propietarios), rebasaban ampliamente las dimensiones medias de los demás caseríos explotados por renteros. Como es obvio, descontando esos casos, las dimensiones medias de las explotaciones agrarias de los inquilinos se reducían notoriamente, quedando muy por debajo de la hectárea.

A esas apreciaciones habría que añadir las vinculadas con las unidades de explotación surgidas de la escisión de varios caseríos (Gartzienea de Alcayaga y Telletxea de Zalain en 1811 e Iturria y Etxeberria de Alcayaga en 1844) de la unidad de propiedad en dos explotaciones, una de ellas a cargo del dueño y la otra a cargo de un inquilino. Con todo, hay que aclarar que las dimensiones de esas ex- 
plotaciones responden a los parámetros habituales respectivos de campesinos propietarios y de campesinos arrendatarios descritos en los Cuadros anteriores.

\section{CUADRO 2: EXPLOTACIONES AGRARIAS} DE LOS INQUILINOS EN 1844.

\begin{tabular}{|l|c|c|c|c|c|c|c|c|c|}
\cline { 2 - 8 } \multicolumn{1}{c|}{} & TP & TA & TFA & TT & CS & VC & LN & CB & CE \\
\hline BEREKOETXEA & & 0,40 & & 0,40 & & 2 & & & 1 \\
BARRENETXEA ZAL 1 & & 1,07 & & 1,07 & & 2 & & & 1 \\
2 & & 0,54 & & 0,54 & & 1 & & 1 & 1 \\
3 & & 1,07 & & 1,07 & & 2 & & & 1 \\
4 & 0,20 & 1,07 & & 1,07 & & 2 & & & 1 \\
AGUSTINBAITA & & 0,40 & 0,60 & & 1 & & 1 & \\
BORDATXARREA & & 0,67 & & 0,67 & & 3 & & & 1 \\
ITURRIA & & 0,94 & & 0,47 & & 1 & & & \\
ETXEBERRIKOBORDA & & 0,54 & & 0,94 & & 3 & & & 1 \\
ERROTALDEKOBORDA & & & & 0,54 & & 2 & & & 1 \\
ERROTA & 0,13 & 1,21 & 0,33 & 1,67 & & 3 & 30 & & 1 \\
BARRENETXEKOBORDA & & 0,80 & & 0,80 & & 2 & & & 1 \\
MAJIRENARENBORDA & & 1,41 & 0,70 & 2,11 & & 3 & 20 & & 1 \\
IPARRAGIRREA 1 & & 1,41 & 0,70 & 2,11 & & 2 & & & 1 \\
2 & & 1,41 & 0,70 & 2,11 & & 1 & & & \\
3 & & 0,47 & & 0,47 & & 2 & & & \\
SOROA & 0,60 & & & 0,60 & & 1 & & & \\
ETXEBERRIA & & 2,21 & & 2,21 & & 2 & & & \\
BARRENETXEA ALK 1 & & 1,14 & & 1,14 & & 2 & & & \\
2 & & 2,28 & & 2,28 & & 3 & & & \\
3 & 0,04 & 0,91 & 0,13 & 1,09 & 0 & 1,9 & 2,4 & 0,1 & 0,6 \\
MEDIA & & & & & \\
\hline
\end{tabular}

NOTA: TA: HECTÁREAS DE TIERRA PROPIA DEDICADAS A CEREAL; TA: HECTAREAS DE TIERRA DE CEREAL ARRENDADAS; TFA: HECTAREAS DE TIERRA FENERAL ARRENDADAS; CAS: CARGAS DE CASTAÑAS; VC: CABEZAS DE GANADO BOYERAL Y VACUNO; LN: CABEZAS DE GANADO CAPRINO Y LANAR; CB: CABEZAS DE GANADO CABALLAR; CE: CABEZAS DE GANADO CERDIO.

FUENTE: CATASTRO DE LESACA DE 1844. ARCHIVO MUNICIPAL DE LESACA. ELABORACIÓN PROPIA.

Acerca de las relaciones de explotación, la característica primordial en esas relaciones entre propietarios y arrendatarios era la de que, según recuerda Cruz Mundet (1991) en su estudio sobre el caserío en Rentería, era el propietario quien escogía al arrendatario, valorando la capacidad de trabajo de su unidad familiar, así como su dotación en aperos, en ganado y en capital. El corolario lógico de esa pauta era que las familias pobres estaban fatalmente condenadas a asumir los caseríos pobres. 
Por otra parte, en todos los casos analizados de arrendamientos de los barrios de Alcayaga y Zalain la renta a pagar por los arrendatarios era renta en metálico. En un caso, el de Matxienea, además de la renta en metálico, el arrendatario debía de pagar al final del quinto año 25 robos de maíz.

Los plazos de arriendo variaban de caserío a caserío e incluso en el caso del mismo. Barrenetxea, por ejemplo, por lo general se arrendaba por 4 años y a veces por 6 o por 2. Majirenarenborda se arrendó por 7 años en 1853 , por 4 en 1859 y 1865 y por 2 en 1870 . La mitad de la casa de Olarenea se dió en renta por un plazo de 4 años. La mitad de Matxienea se alquiló en principio en 1865 para 5 años, aún cuando en 1869 se rescindió el contrato porque el arrendatario había arrendado otro caserío, condonándole el arrendador el pago de 25 robos de maíz que debía haber pagado al final del quinto año, en 1870. Por último, los caseríos Berekoetxea, Iparragirrea, Telletxekoborda y Aldategia tenían unos plazos de arriendo de 6, 9, 8 y 10 años respectivamente.

En la comarca de Cinco Villas solía ser muy habitual que, además del pago de la renta, el arrendatario debiera efectuar de forma obligada el caleado de la tierra y también en ocasiones algunas labores suplementarias como plantar arbolado, roturar tierras, llevar al propietario carros de leña y cargas de manzanas. En el caso de los contratos analizados de Zalain y Alcayaga solamente se observan esos trabajos suplementarios en los casos de Telletxekoborda, Majirenarenborda, Iparragirrea y Aldategia. Mientras en el primero de esos caseríos el arrendatario se debía de hacer cargo de la construcción de una ladera a lo largo del edificio que alquilaba y en el segundo debía plantar varias plantas de manzanos en una ocasión y de castaños en otra, en los otros dos debían de hacer frente al caleado de las tierras. Asimismo, aunque en ocasiones en las Cinco Villas esos trabajos suplementarios añadidos le suponían al arrendatario una rebaja de la renta, pactada ya en el mismo contrato de arrendamiento, esas rebajas no se observan en ninguno de los casos observados de Alcayaga y de Zalain.

Si bien la totalidad de los contratos de arrendamiento trabajados para los barrios de Alcayaga y Zalain muestran que la renta a pagar era en metálico, puede pensarse que en muchos casos correspondientes a los arrendamientos que no han dejado huella documental (que, recordémoslo, eran la mayoría) la renta era en especie pagándose la mitad de la cosecha, en régimen, pues, de aparcería. La base de esa afirmación la encontramos en dos indicios de Lesaca y de Aranaz que muestran lo arraigado de esa práctica en la comarca.

El primero de ellos es de 1813. Según el «Estado de los subministros hechos en frutos a las tropas y brigadas» y que comprende los perjuicios ocasionados en la cosecha por las tropas angloportuguesas, de los 217 inquilinos que en él figuran, 62 (el 28,6 por ciento) por lo menos pagaba la renta de la tierra y caserío con la mitad de la cosecha del maíz y de la alubia ${ }^{14}$.

14 Archivo General de Navarra (AGN), Sección de Protocolos Notariales, Notaria de Lesaca, Escribano N. J. Alduncin, 1813, legajo 23, documento 68. 
El segundo de ellos procede del catastro de Aranaz de 1822 en el que se indica «la práctica que se observa de darse las fincas al colono cultivador a medio fruto con el propietario» ${ }^{15}$.

De cualquier forma, es más que posible que la renta en metálico se generalizara en el curso del tiempo, siendo más generalizada la aparcería conforma más retrocedamos en el tiempo. En los contratos de aparcería los propietarios supervisaban constantemente el funcionamiento de la explotación. Los costes de explotación corrían a cargo del arrendatario y el reparto de los beneficios era a medias, debiendo transportar el casero los productos hasta donde se lo ordenara el amo y debiendo convertir la manzana en sidra. Asimismo, en ocasiones los dueños se reservaban el aprovechamiento de leña y de frutos de algunos árboles y por lo general el colono debía realizar ciertas ofrendas y regalos en fechas señaladas. Obviamente, el colono se comprometía a la conservación del caserío y de sus tierras, encalando éstas, plantando viveros, etc.

En el caso concreto de Alcayaga y Zalain sabemos de un caso, que incumbía a varios hogares de arrendatarios que compartían el arriendo del mismo caserío, en el que el arriendo seguía pautas de aparcería. Ese caso es el del caserío Iparragirrea por haber publicado Julio Caro Baroja ${ }^{16}$ las condiciones que se ponían a los inquilinos que la habitaban.

Ya por último, para finalizar con este apartado es importante señalar que la pluriactividad era una seña de identidad del campesinado propietario de estos barrios, así como del arrendatario, tal y como sucedía en todas partes. Los limitados recursos de las empresas agrarias de los propietarios cultivadores directos y las más limitadas todavía de los arrendatarios (que encima debían de abonar el pago de una renta que, por lo general, era en metálico, pero que también podía equivaler a la mitad de lo cosechado) debían de ser complementadas a través de la aplicación a labores pluriactivas (relacionadas con actividades vinculadas con la artesanía, la industria localizada en ámbitos rurales dispersa o no, el monte, los servicios y la venta estacional de fuerza de trabajo) para asegurar la supervivencia y la reproducción de estas economías familiares. El grueso de esas pautas pluriactivas tenía que ver con actividades siderúrgicas. Hay que tener en cuenta que en Lesaca existieron hasta 1870 cuatro ferrerías tradicionales y que en Vera hubo hasta 1850 otra. Además, a partir de 1855 en Vera hubo un horno alto, construido sobre la antigua ferrería de Olandia al que a mediados de los años sesenta se asociaría una fábrica de laminar hierro en el solar en el que después de 1881 se asentaría la Fábrica de Fundiciones.

15 AGN, Sección Estadística, legajo 40, carpeta 26.

16 Caro Baroja, Julio, De la vida rural vasca, San Sebastián, 1974, pp. 78-81. 


\section{LA ESTRUCTURA DE LOS HOGARES A PARTIR DE LOS CENSOS DE POBLACIÓN}

Al igual que hemos hecho en relación con el tamaño, la composición y la relación entre activos potenciales y consumidores netos, hemos estudiado la estructura de los hogares de los barrios de Alcayaga y Zalain entre 1824 y 1894 a través del análisis de la información presente en las listas de habitantes de los años $1824,1832,1841,1850,1860,1867,1871,1880,1886$ y 1894. Hemos complementado un enfoque de carácter estático por medio del que estudiamos los datos suministrados en relación con los diversos aspectos considerados por cada lista de habitantes de forma separada con una perspectiva de carácter dinámico con la que estudiamos la evolución de diversos aspectos en todas aquéllas familias para las que contamos con información en la totalidad o en la mayoría de los cortes censales y que como se verá llegan a ser una cifra relativamente alta.

Nuestro análisis de la estructura descansa en el sistema de clasificación de los hogares de Laslett y del grupo de Cambridge ${ }^{17}$, que discierne los siguientes cinco tipos: 1) Hogares solitarios: constituídos por personas que viven solas 2) Hogares sin estructura familiar: con dos o más personas solteras, por lo general hermanos. 3) Hogares simples o nucleares: compuestos por un núcleo conyugal con o sin hijos o por alguno de los padres viudo con los hijos que vivan con él. 4) Hogares extensos: hogares en los que vive una persona viuda o un núcleo conyugal, con o sin hijos, acompañado de al menos un pariente soltero o viudo del tipo que sea. 5) Hogares múltiples: en los que viven dos núcleos conyugales, con o sin hijos o con o sin más parientes del estado civil que sea, unidos por vínculos de filiación por lo general. Como es sabido, la suma de los hogares extensos y múltiples da lugar a los hogares complejos.

¿Para qué sirve el estudio de la estructura de los hogares? El estudio de la estructura de los hogares tiene una tremenda importancia en el estudio de las sociedades del pasado ya que, a través de la morfología que adoptan los hogares, podemos reconstruir el tipo de familia a partir del conocimiento de la pauta de establecimiento de los matrimonios y de la pauta de transmisión de los patrimonios. Esto es así porque existen unos lazos bastantes evidentes entre los porcentajes de hogares complejos y el tipo de familia predominante.

Antes de seguir, es importante recordar que en el contexto vasco, así como en el español, existían dos modelos de familia: la familia nuclear y la familia troncal, ambos relacionados con pautas concretas de transmisión de los patrimonios y de establecimiento de las parejas recién casadas.

La familia nuclear se sustentaba en el hecho de que un nuevo matrimonio implicaba la creación de un nuevo grupo doméstico (es decir, la pauta de establecimiento seguida era neolocal) y en una forma de transmisión del patrimo-

17 LASLETT; Peter, «La famille et le menaje: approches historiques», en Annales ESC, 1972, pp. 847-872; LASLETT, Peter y HAMMEL, Eugene, «Comparing household structures over time and between cultures», en Comparative studies in society and history, 16, pp. 73-109.

Hispania, LXIII/1, núm. 213 (2003) 199-230 
nio según la cual la transmisión de los bienes se basaba en un reparto igualitario entre los hijos. El ciclo de vida de una familia de pautas rigurosamente nucleares podría atravesar por la siguiente serie de etapas: una primera etapa de constitución de una nueva unidad familiar en la que solamente están presentes los dos cónyuges; una segunda etapa en la que hijos que progresivamente van naciendo se van incorporando al hogar; una tercera etapa en la que los hijos progresivamente van saliendo del hogar conforme se van casando y van constituyendo grupos domésticos autónomos; una cuarta etapa en la que, tras el matrimonio de todos los hijos, los padres vuelven a estar solos; y una quinta y última etapa en la que, tras la muerte de uno de ellos, la unidad familiar esta constituída por una persona viuda hasta el momento en que esta fallezca y la unidad familiar desaparezca con ella. Obviamente, esa secuencia se vería alterada si la muerte de uno o de los dos cónyuges se produjera con anterioridad al momento en que la totalidad de los hijos hubiese abandonado la casa paterna.

Por su parte, el modelo troncal se asentaba sobre una regla de establecimiento patrilocal, por la cual los matrimonios se afincaban en casa de los padres de uno de los cónyuges, corresidiendo diversos núcleos conyugales en algún momento concreto del ciclo de vida familiar, y sobre un sistema sucesorio inigualitario en el que un hijo o hija recibía la totalidad del patrimonio de la casa.

La familia troncal se basa, por lo tanto, en la presencia de una línea genealógica que se corresponde habitualmente con la presencia de dos núcleos conyugales, ligados entre sí por vínculos paterno-filiales. Asimismo, en la composición de estos grupos domésticos quedarán incluídos junto a los miembros de los núcleos conyugales de la línea troncal y los descendientes del núcleo conyugal más joven, los parientes colaterales solteros que no hayan alcanzado la edad de tomar estado matrimonial o que hayan decidido permanecer célibes en la casa familiar. Los parientes solteros de las familias troncales pueden abandonar el hogar paterno, recibiendo una compensación en metálico o en especie que les ayude a contraer matrimonio con el heredero o heredera de otro patrimonio en la unidad familiar de éste último, a contraer matrimonio neolocal con otra persona no heredera de ningún otro patrimonio o a montar negocios o ejercer profesiones fuera del entorno familiar y en estado civil de soltería. Los parientes solteros que no deseen abandonar la casa paterna, pueden permanecer en ella al cuidado y manutención del titular del patrimonio y trabajando en beneficio de la hacienda familiar. Asi pues, en los momentos de máxima amplitud de este tipo de familia podían convivir hasta tres generaciones dentro de un mismo grupo doméstico: la de los padres y tíos y tías solteros del núcleo conyugal del que forma parte el hijo o hija de la casa instituído como heredero; la del núcleo conyugal heredero y de sus hermanos y hermanas solteros; $y$, por último, la de los hijos e hijas de ese núcleo conyugal heredero.

La mención de la corresidencia entre donadores y donatarios propia de la familia troncal suele ser la primera condición que sigue a la donación de los bienes en los contratos matrimoniales. Esta claúsula se expresa habitualmente así: «que los donadores y donatarios bayan de vivir en una casa, mesa y compañía, co- 
rriendo los últimos, desde el día que contraigan matrimonio, que es cuando principiará a surtir sus efectos este contrato, con la dirección, gobierno y mando, sin perjuicio de conservar a los primeros todo el respeto devido". Asimismo, el cuidado y manutención de los padres suele recogerse de la siguiente forma: «que será obligación de los mismos donatarios el alimentar, vestir y calzar a sus padres donadores sanos y enfermos, asistiéndoles con todo lo necesario, y el bacerles a su fallecimiento el entierro de su clase $y$ bonras de cuatro días, sin exijir que en vida trabajen más que lo que buenamente puedan y permitan sus fuerzas

La mención de la corresidencia de los donatarios, además de con los donadores, con los hermanos segundones de quien hereda e incluso con los tíos solteros que deseen permanecer en la casa suele recogerse cuando se habla de la obligación de aquéllos para con éstos de "mantenerlos, vestirlos y asistirles sanos $y$ enfermos en su compañia, mientras quieran permanecer en ella en estado de soltero, trabajando lo que puedan en beneficio de la casa. Si mueren sin casarse les costearán por todos sus derechos, el entierro y las funciones de honras de cuatro días».

El ciclo de vida de una familia de parámetros troncales presenta una amplia gama de etapas. En principio, cabe pensar que en el ciclo de vida de la familia troncal han de constatarse forzosamente tres etapas: una etapa primera en la que el núcleo conyugal del hijo o hija designado como heredero se establece junto a uno o los dos padres de ese hijo o hija; una segunda etapa en la que han fallecido los padres y el núcleo conyugal de aquel hijo o hija instituido como heredero convive con sus hijos; y una tercera etapa en la que se vuelve a la situación inicial en el momento en que junto a el núcleo conyugal entonces instituido como heredero se instala el hijo o hija y su cónyuge elegidos ahora como nuevos sucesores. Ahora bien, además de esas tres etapas ineludibles, la familia troncal podía dar lugar a una variación mucho mayor de situaciones debido a las posibilidades que suponía el derecho que este sistema sucesorio y familiar proporcionaba a los hijos e hijas de la casa que no eran designados como herederos de continuar viviendo en ella en unión del núcleo conyugal constituido como sucesor, siempre y cuando permanecieran en estado civil de soltería.

Bajo todo ello, ahondaremos ahora en la cuestión de los nexos existentes entre la tipología clasificatoria de los hogares que hemos utilizado y los distintos sistemas familiares, troncal o nuclear.

En lo que se refiere a la familia nuclear neolocal, de acuerdo con su ciclo de vida genuino, es lícito afirmar que la morfología concreta que puede adoptar una familia de ese tipo en un momento determinado del tiempo se traduce en las siguientes tres categorías de la tipología clasificatoria anteriormente reseñada: hogares nucleares o simples en los que un núcleo conyugal se presenta con hijos o sin hijos; hogares solitarios en la que una persona viuda, abandonada por sus hijos, constituye la unidad familiar; y hogares sin estructura en el caso de que, muertos los padres, el hogar esté constituído únicamente por sus hijos solteros.

Por su parte, el ciclo de vida de la familia troncal podía dar lugar a las siguientes morfologías de los hogares, según el sistema de clasificación de los 
grupos domésticos que hemos propuesto, en los momentos puntuales del tiempo a los que se refieren las listas nominales de habitantes: hogares simples (en el caso de que la familia troncal atravesara la etapa de su ciclo de vida en la que los miembros de la unidad conyugal designada como heredera vivieran únicamente con sus hijos, fallecidos sus padres y sin que, por circunstancias diversas, no cohabitara junto a ellos ningún pariente soltero) u hogares complejos (en el caso de que la familia atravesara la etapa de su ciclo vital en la que los miembros de la unidad conyugal heredera vivieran con o sin sus hijos, corresidiendo con ellos los dos o alguno de los padres del heredero del patrimonio o también uno o varios parientes solteros de su misma generación o de la generación anterior).

Como consecuencia del hecho de que las familias troncales puedan presentarse en las fotografías fijas que dan las listas nominales de habitantes como diseminadas en hogares simples, hogares extensos y hogares múltiples, se plantea lógicamente una cuestión: la de cuál debe ser el peso relativo de cada uno de esos tipos de hogares de cara a poder postular que la familia troncal es el sistema familiar socialmente predominante en una sociedad.

Acerca de esto, ya desde los años setenta diversos autores ${ }^{18}$ negaron que empíricamente pudieran localizarse ejemplos que traslucieran ese predominio social del sistema familiar troncal en superioridades estadísticas evidentes (como la de que la suma de los hogares extensos y múltiples alcanzara proporciones superiores al 50 por ciento del total de los hogares de un universo demográfico determinado) debido al impacto de la mortalidad que hacía que familias en rigor troncales aparecieran documentalmente como hogares simples del tipo 3. En opinión de esos mismos autores, se puede hablar del predominio social de la familia troncal cuando la proporción de hogares extensos y múltiples supera el 25 por ciento del total de los hogares.

Dicho todo ello y recalcando que, de acuerdo con la clasificación que estamos utilizando, una proporción de hogares complejos de 20 o del 25 por ciento resulta ya ser indicativa del predominio social de la familia troncal debido a que las familias constituídas bajo los parámetros de la troncalidad aparecen, según la fase del ciclo vital en que se encuentren, como hogares del tipo simple o del tipo complejo por efecto del fallecimiento de algunos de los miembros de la familia, vayamos ahora con el comentario de los cuadros estadísticos relativos a la estructura de los hogares de los barrios lesacarras de Alcayaga y Zalain.

18 BerKNER, Lutz $\mathrm{K}$, «The stem family and the developmental cycle of the peasant household», American History Review, 1972, 77, 7, 2, pp. 398-418; BERKNER, Lutz K., "The use and misuse of census data for the historical analysis of family structures" Journal of Interdisciplinary History, 1976, V, 4, pp. 721-738; COLLOMP, Alain, «Ménage et famille: etudes comparatives sur la dimension et la structure du groupe domestique», Annales ESC, 1974, 29, pp. 777.786; FINESOURIAC, Agnes, "La famille souche pyrenéenne au XIX siécle: quelques reflexions de méthode», Annales ESC, 1977, 32, pp. 478-487.

Hispania, LXIII/1, núm. 213 (2003) 199-230 
3.1. La estructura de los hogares a partir de los censos de población. Un análisis estático.

En el Cuadro 3 vemos los tipos de hogar existentes en Alcayaga y Zalain en las listas de habitantes de las fechas de 1824, 1832, 1841, 1850, 1860, 1867, $1871,1880,1886$ y 1894 conservadas en el archivo municipal de Lesaca. El hecho más significativo que se desprende de los datos de ese Cuadro 3 es el de que el porcentaje de los hogares complejos registra un fuerte descenso desde unos altos niveles que llegan casi al 50 por ciento en 1824 y 1832 hasta unos niveles en torno al 30 entre 1841 y 1860 y hasta unos niveles situados unos diez puntos porcentuales más abajo en 1867 y 1871, iniciando después una tendencia al alza que sitúa la complejidad familiar de estos barrios en torno al 35,0 por ciento en 1880 y 1886 y en el 50,0 (el mayor porcentaje de todo el periodo) en 1894.

\section{CUADRO 3: ESTRUCTURA DEL HOGAR EN ALCAYAGA Y ZALAIN ENTRE 1824 Y 1894.}

\begin{tabular}{|l|c|c|c|c|c|c|c|c|c|c|}
\cline { 2 - 10 } \multicolumn{1}{c|}{} & \multicolumn{2}{c|}{ SOLITARIOS } & \multicolumn{2}{c|}{ SIN EST. } & \multicolumn{2}{c|}{ SIMPLES } & \multicolumn{2}{c|}{ COMPLEJOS } & \multicolumn{2}{c|}{ TOTALES } \\
\cline { 2 - 10 } \multicolumn{1}{c|}{} & NUM & $\%$ & NUM & $\%$ & NUM & $\%$ & NUM & $\%$ & NUM & $\%$ \\
\hline 1824 & 0 & 0,0 & 0 & 0,0 & 20 & 52,6 & 18 & 47,4 & 38 & 100 \\
1832 & 0 & 0,0 & 0 & 0,0 & 20 & 52,6 & 18 & 47,4 & 38 & 100 \\
1841 & 0 & 0,0 & 0 & 0,0 & 31 & 70,4 & 13 & 29,5 & 44 & 99,9 \\
1850 & 2 & 4,4 & 0 & 0,0 & 29 & 64,4 & 14 & 31,1 & 45 & 99,9 \\
1860 & 1 & 2,4 & 0 & 0,0 & 29 & 69,0 & 12 & 28,6 & 42 & 100 \\
1867 & 3 & 6,8 & 1 & 2,3 & 31 & 70,4 & 9 & 20,4 & 44 & 99,9 \\
1871 & 1 & 2,5 & 0 & 0,0 & 30 & 75,0 & 9 & 22,5 & 40 & 100 \\
1880 & 0 & 0,0 & 1 & 2,5 & 25 & 62,5 & 14 & 35,0 & 40 & 100 \\
1886 & 1 & 2,4 & 1 & 2,4 & 25 & 61,0 & 14 & 34,1 & 41 & 99,9 \\
1894 & 0 & 0,0 & 3 & 7,5 & 17 & 42,5 & 20 & 50,0 & 40 & 100 \\
\hline
\end{tabular}

FUENTE: CENSOS NOMINALES DE LAS FECHAS RESPECTIVAS. ARCHIVO MUNICIPAL DE LESACA. ELABORACIÓN PROPIA.

A pesar de su disminución a partir de 1841 en relación con los niveles alcanzados en las dos primeras fechas de 1824 y 1832 y del aumento constatado en relación con los bajos niveles de 1867 y 1871, todas las proporciones de hogares complejos del periodo 1824-1894 sugieren el predominio social de la familia troncal en los dos barrios de Alcayaga y Zalain.

Acerca de la interpretación de esos porcentajes, puede resultar útil realizar una comparación con los resultados conseguidos en otras zonas próximas de la Vasconia cantábrica. Limitándonos en un primer plano a localidades cercanas estudiadas por diversos autores, hay que subrayar que los porcentajes de hogares complejos de Alcayaga y de Zalain en las fechas de 1841, 1850 y 1860 (no 
así los de 1824 y 1832) concuerdan con los porcentajes calculados en otras localidades de las Cinco Villas como Vera y Echalar por autores como Erdozáin y Mikelarena o como Douglass. En relación con Vera, las proporciones de hogares complejos se situaban en esta localidad en el 24,3 por ciento en 1786 y en el 27,1 en 1857 , ascendiendo en la zona de caseríos de ese municipio, zona ésta parangonable por su contexto socioeconómico al ámbito constituído por el conjunto de los dos barrios de Alcayaga y Zalain, al 30,3 en la primera fecha y al 36,0 en la segunda ${ }^{19}$. En relación con Echalar, las proporciones de complejidad familiar en 1842 y en 1861 se situaban en el 28,0 y en el 31,1 por ciento respectivamente sobre el total de grupos domésticos ${ }^{20}$. Asimismo, los porcentajes mencionados de complejidad familiar son hondamente similares a la proporción del 28,8 estimada por Urrutikoetxea ${ }^{21}$ para Irún en 1845 , un Irún que en tamaño y estructura socieconómica de la población se parecería bastante a Vera. Por contra, son sensiblemente más bajas que la proporción del 42,7 estimada por Cruz Mundet ${ }^{22}$ para Rentería en 1857. Asimismo, también son sensiblemente inferiores a las proporciones, siempre por encima del 30 por ciento y en muchos casos hasta del 40 , estimadas por Mikelarena ${ }^{23}$ en muchos valles del norte de Navarra en 1786. De todo ello se puede concluir que, a pesar de ser la familia troncal el modelo familiar predominante en Alcayaga y en Zalain en todo el periodo que va de 1824 a 1860 , su arraigo no era tan fuerte a partir de 1841 como en la mayoría del norte de Navarra, quizás por el peso del campesinado arrendatario, cuya influencia en aquellos valores se explicará más adelante.

Centrándonos ahora en la cuestión del descenso de la complejidad familiar evidenciado a partir de 1841 y del aumento posterior constatado en relación con los bajos niveles de 1867 y 1871 en los barrios estudiados, a nuestro juicio, se explica por la incidencia de diferentes factores.

Un primer factor es el de las transformación acaecidas en la estructura social de los dos barrios. Mientras el número de los hogares de propietarios se mantuvo bastante estable a lo largo de todo el periodo 1824-1894 entre los 17 y los 20, creciendo a partir de 1841 por efecto sobre todo de las divisiones de patrimonios que se registran en algunos caseríos como Matxienea y Errandonea, el número de los hogares arrendatarios aumentó desde las 22 unidades en

19 ERdozÁin, Pilar y Mikelarena, Fernando, «Familia y Hogar en Vera en los siglos XVIII y XIX», Historia de Vera, 1500-1850, Cuadernos del Centro de Estudios Bidasoa, 1998, 1, pp. 49-80.

20 Douglass, William, «The basque stem family household: mith or reality», Journal of Family History, 13,1, pp. 75-90.

21 URRUTIKOETXEA, José, op. cit

22 Cruz Mundet, José Ramon, op. cit.

23 MikelareNA, Fernando, «Doce mil hogares rurales navarros del siglo XVIII: estructura, tamaño y composición", Cuadernos de Sección de Geografía e Historia de Eusko Ikaskuntza-Sociedad de Estudios Vascos, 1994, 22, pp. 171-212; Mikelarena PeÑA, Fernando, Demografía y familia en la Navarra tradicional, Pamplona, 1995. 
1824 y 1832 hasta las 27 en 1841 , constatándose posteriormente 26 en 1850 y 24 en 1860 y 1867 y entre 20 y 21 en 1871,1880 y 1886.

Como es lógico, ese aumento de los grupos domésticos arrendatarios en cuatro o cinco unidades, así como la disminución posterior en la misma cuantía, vehiculizaría a la baja primero y al alza después la proporción de los hogares complejos sobre el total de hogares porque el seguimiento de las pautas troncales de estructuración familiar en ese sector era menor que entre los propietarios a causa de carencia en aquéllos de bienes inmuebles, requisito esencial para la existencia efectiva del régimen sucesorio de heredero único, de la pauta de establecimiento patrilocal de los matrimonios y de la familia troncal en suma. Si una familia carecía de bienes propios, los padres no podían entonces designar a ningún hijo heredero de sus bienes por ser éstos inexistentes, y no podían consecuentemente animarle a corresidir con ellos y a ampararles en su vejez ${ }^{24}$. Ese hecho del menor seguimiento de la complejidad familiar entre los arrendatarios se constata claramente en el Cuadro 4 en el que figuran las proporciones de los diversos tipos de hogares en el sector de propietarios y el de arrendatarios. Mientras entre los primeros en porcentaje de hogares complejos llega a ser del 50,0 por ciento, entre los segundos se limitaba a ser del 12,5 por ciento. Con todo, si bien la falta de un incentivo material para la corresidencia entre los padres y uno de sus hijos explica la menor proporción de hogares complejos entre los inquilinos y la menor incidencia, por tanto, de la familia troncal, también hay que tener en cuenta que ese porcentaje del 12,5 por ciento demuestra un relativo seguimiento de las pautas troncales entre los inquilinos, explicable por el intento de imitación de los integrantes de este sector social de la norma dominante y preferente en el conjunto de la sociedad, así como por la incidencia de situaciones de corresidencia de un hijo o hija y de su cónyuge con el padre o los padres, situaciones provocadas no por vínculos materiales o de búsqueda de compensación económica, sino por vínculos afectivos y de solidaridad con las personas ancianas. De hecho, tal y como después indicaremos en las reconstrucciones dinámicas de familias arrendatarias que hemos realizado hemos comprobado que durante la segunda mitad del ochocientos se advierte en ellas una clara tendencia a la complejidad en su estructura.

El segundo factor es el de que entre los mismos arrendatarios el seguimiento de las pautas troncales disminuyó en intensidad a lo largo del tiempo. Así por ejemplo, mientras en 1860 los arrendatarios tenían una complejidad familiar cifrada en el 12,5 por ciento, tal y como se vió en el Cuadro 4, en 1824 y en 1832 se registra una complejidad de más del doble. En ambos casos 6 hogares de ese sector sobre un total de 22 aparecen como complejos: en la primera fecha en caseríos como Barrenetxea de Alcayaga, Iparragirrea, Etxeberria, Ga-

24 Mikelarena Peña, F.: «Doce mil hogares rurales..., pp.197-198; MikelarenA, F., Demografía y familia...., pp. 254-257; ERdOZÁIn AzPILICUETA, P., Propiedad, familia y trabajo en la Navarra contemporánea, Pamplona, 1999, pp. 193-197.

Hispania, LXIII/1, núm. 213 (2003) 199-230 
raikoetxea, Barrenetxea de Zalain e Iturria; en la segunda fecha en caseríos como Barrenetxea de Alcayaga, Iparragirrea, Borda, Berekoetxea, Bordatxarrea y Agustinbaita. A la vez, posteriormente, tal y como después indicaremos en las reconstrucciones dinámicas de familias arrendatarias que hemos realizado, hemos comprobado que durante la segunda mitad del ochocientos se advierte en ellas una clara tendencia a la complejidad en su estructura.

\section{CUADRO 4: ESTRUCTURA DEL HOGAR ENTRE CAMPESINOS PROPIETARIOS Y ARRENDATARIOS EN ALCAYAGA Y ZALAIN EN 1860.}

\begin{tabular}{|l|l|l|l|l|l|l|l|l|l|l|}
\cline { 2 - 11 } \multicolumn{1}{c|}{} & \multicolumn{2}{c|}{ SOLITARIOS } & \multicolumn{2}{c|}{ SIN EST. } & \multicolumn{2}{c|}{ SIMPLES } & \multicolumn{2}{c|}{ COMPLEJOS } & \multicolumn{2}{c|}{ TOTALES } \\
\cline { 2 - 6 } \multicolumn{1}{c|}{} & ABS & $\%$ & ABS & $\%$ & ABS & $\%$ & ABS & $\%$ & ABS & $\%$ \\
\hline PROPIET. & 1 & 5,6 & 0 & 0,0 & 8 & 44,4 & 9 & 50,0 & 18 & 100 \\
ARRENDAT. & 0 & 0,0 & 0 & 0,0 & 21 & 87,5 & 3 & 12,5 & 24 & 100 \\
\hline
\end{tabular}

FUENTE: CENSOS NOMINALES DE LAS FECHAS RESPECTIVAS. ARCHIVO MUNICIPAL DE LESACA. ELABORACIÓN PROPIA.

Un tercer factor que también es preciso considerar es el del propio momento del ciclo de vida familiar en que se encontraban los hogares. En el Cuadro 5 presentamos la distribución de los hogares de los barrios de Alcayaga y Zalain en las distintas fechas censales de acuerdo con la edad de su cabeza de familia, según tuviera entre 20 y 29 años, entre 30 y 39, entre 40 y 49, entre 50 y 59 o más de 60 . Teniendo presente que en el caso de los hogares complejos siempre se ha considerado, por razones de homogeneización estadística, como cabeza de familia al varón casado o viudo (y en su defecto a la mujer viuda) más joven, según puede verse, los hogares complejos encabezados por individuos de menos de 50 años experimentaron un descenso notable a partir de 1841 , volviendo a crecer tras 1880 . De representar un 65,8 por ciento del total en 1824 y 1832 , supusieron un 52,3 por ciento en 1841 , un 55,6 en 1850 , un 47,6 en 1860 , un 47,7 en 1867, un 40,0 en 1871, un 62,5 en 1880 , un 56,1 en 1886 y un 70 en 1894 . Esos porcentajes son de suma importancia como argumento para nuestros fines ya que justamente, de acuerdo con el ciclo de vida de la familia troncal, tal y como se aprecia en el Cuadro siguiente, el número 6, en el que se presentan las proporciones de hogares complejos sobre el total de hogares de cada tramo de edad del cabeza de familia en las diversas fechas, en los hogares encabezados por personas de menos de 50 años la complejidad familiar era, por lo general, sustancialmente más alta que en los encabezados por personas de más de esa edad.

Por lo tanto, la evolución de la complejidad familiar en estos dos barrios en el período considerado no responde a ningún proceso histórico sino a cambios relacionados con la estructura social y demográfica interna de una muestra pequeña de familias. 
CUADRO 5: DISTRIBUCIÓN DE LOS HOGARES DE CADA FECHA DE ALCAYAGA Y ZALAIN SEGÚN LA EDAD DEL CABEZA DE FAMILIA. NÚMEROS ABSOLUTOS.

\begin{tabular}{|l|r|r|r|r|r|r|r|r|r|r|}
\cline { 2 - 10 } \multicolumn{1}{c|}{} & 1824 & 1832 & 1841 & 1850 & 1860 & 1867 & 1871 & 1880 & 1886 & 1894 \\
\hline $20-29$ & 5 & 2 & 2 & 4 & 2 & 4 & 1 & 3 & 1 & 5 \\
$30-39$ & 11 & 9 & 10 & 14 & 9 & 7 & 8 & 8 & 8 & 10 \\
$40-49$ & 9 & 14 & 11 & 7 & 9 & 10 & 7 & 14 & 14 & 13 \\
$50-59$ & 8 & 9 & 15 & 11 & 7 & 6 & 10 & 5 & 9 & 7 \\
$60-$ & 5 & 4 & 6 & 9 & 15 & 17 & 14 & 10 & 9 & 5 \\
\hline TOTAL & 38 & 38 & 44 & 45 & 42 & 44 & 40 & 40 & 41 & 40 \\
\hline
\end{tabular}

FUENTE: CENSOS DE LAS DISTINTAS FECHAS. ARCHIVO MUNICIPAL DE LESACA. ELABORACIÓN PROPIA.

CUADRO 6: PORCENTAJES DE HOGARES COMPLEJOS SEGÚN LA EDAD DEL CABEZA DE FAMILIA EN LAS DIVERSAS FECHAS CENSALES EN ALCAYAGA Y ZALAIN.

\begin{tabular}{|l|c|r|r|r|r|}
\cline { 2 - 6 } \multicolumn{1}{c|}{} & 1824 & 1832 & 1841 & 1850 & 1860 \\
\hline $20-29$ & 40,0 & 100,0 & 50,0 & 0,0 & 0,0 \\
$30-39$ & 90,9 & 55,6 & 50,0 & 42,9 & 22,2 \\
$40-49$ & 66,7 & 42,9 & 18,2 & 0,0 & 33,3 \\
$50-59$ & 0,0 & 55,6 & 13,3 & 54,5 & 14,3 \\
$60-$ & 0,0 & 0,0 & 50,0 & 22,2 & 40,0 \\
\hline TOTAL & 47,4 & 47,4 & 29,5 & 31,1 & 28,6 \\
\hline
\end{tabular}

\begin{tabular}{|l|r|r|r|r|l|}
\cline { 2 - 6 } \multicolumn{1}{c|}{} & 1867 & 1871 & 1880 & 1886 & 1894 \\
\hline $20-29$ & 50,0 & 100,0 & 66,7 & 100,0 & 80,0 \\
$30-39$ & 14,3 & 25,0 & 62,5 & 37,5 & 60,0 \\
$40-49$ & 30,0 & 28,6 & 35,7 & 35,7 & 38,5 \\
$50-59$ & 0,0 & 10,0 & 20,0 & 33,3 & 85,7 \\
$60-$ & 17,6 & 21,4 & 10,0 & 22,2 & 80,0 \\
\hline TOTAL & 20,4 & 22,5 & 35,0 & 34,1 & 50,0 \\
\hline
\end{tabular}

FUENTE: CENSOS DE LAS DISTINTAS FECHAS. ARCHIVO MUNICIPAL DE LESACA. ELABORACIÓN PROPIA.

3.2. La estructura de los hogares a partir de los censos de población. Un análisis dinámico.

Además del análisis estático que hemos llevado a cabo a partir de las informaciones trabajadas de cada censo, equiparables en síntesis a fotografías fijas de los hogares en momentos concretos del tiempo, hemos realizado un análisis dinámico a través de la reconstrucción de las familias presentes en los recuentos de diversas fechas. En total, hemos podido reconstruir 28 casos.

Hispania, LXIII/1, núm. 213 (2003) 199-230 
De entre esos 28 casos, en 17 se ha podido reconstruir las evoluciones de otras tantas familias a lo largo de los diez cortes censales existentes entre 1824 y 1894. Esas 17 familias para las que se han reunido datos procedentes de los diez recuentos del periodo de 70 años que va de 1824 a 1894 en su inmensa mayoría eran familias del campesinado propietario. Son 13 las familias campesinas propietarias: las dueñas de Telletxea (habitantes hasta 1870 en dicho caserío y residentes después de esa fecha en Telletxekoetxeberria), Landakoetxea, Peritxenea, Iturria, Errotaldea, Mikelperitzenea, Maddalenbaita (de hecho, una casa que no era físicamente independiente sino que era parte de Mikelperitzenea), Gartzienea, Errandonea, Garaikoetxea, Martiñenea, Matxienea y Borda de Alcayaga. Por su parte, para el conjunto del periodo contamos con informaciones de cuatro familias arrendatarias: una de ellas vivió en Barrenetxea de Zalain; otra residió en cuatro caseríos diferentes (Bordatxarrea, Martiñenea, Telletxea y Etxeberria de Alcayaga); otra en Borda de Zalain y otra en Garaikoetxea y en Marisconea.

En relación con otras cinco familias tenemos información para diversos cortes censales que cubren un periodo cronológico bastante amplio que se inicia en 1824. En uno de esos casos, el de la familia propietaria de Bertizbaita, se ha conseguido cubrir el periodo 1824-1886, faltando por lo tanto la información relativa a un corte: el de 1894 . En el caso de la familia residente en Berekoetxea primero y en Olarenea después, familia arrendataria, nos faltan únicamente los dos últimos cortes censales: 1886 y 1894 . Por último, se ha conseguido reconstruir la evolución durante el periodo 1824-1867 para dos familias propietarias (residentes en Olarenea y Etxeberria) y para una familia arrendataria que residió en Barrenetxea de Zalain.

Para terminar, se ha conseguido reconstruir la evolución durante periodo de entre 30 y 40 años de una familia propietaria (la de Aldategia entre 1850 y 1894), así como las de otras cinco familias arrendatarias: la que habitó en Soroa entre 1832 y 1860 ; tres que habitaron entre 1850 y 1894 en Barrenetxea de Zalain, en Barrenetxea e Iparragirrea, y en Etxeberrikoborda y Majirenenborda; y la que residió entre 1860-1894 en Barrenetxea de Alcayaga.

Asi pues, en suma, de las 28 familias reconstruídas 17 son de familias propietarias y las 11 restantes de familias arrendatarias. Las reconstrucciones de las primeras son de duración más larga que las de las segundas. Hay que señalar también que la totalidad de las familias propietarias ha podido ser reconstruída.

En el Cuadro número 7 presentamos la estructura del hogar de las 17 familias propietarias en las diversas fechas censales del periodo 1824-1894 para las que contamos con datos sobre ellas. De ese Cuadro pueden extraerse una conclusión primordial: todas esas 17 familias propietarias, con la sola excepción de Errotaldea (en la que por la temprana muerte de los progenitores no dió tiempo a que en las fechas estudiadas se presentaran formas complejas de residencia, siendo los hogares de ese linaje en los diez momentos de estructura nuclear, salvo en un año en que fue sin estructura por convivir los dos hermanos solteros sin ningún otro pariente más) tuvieron estructuras compleja en diversos momentos 
del ciclo vital de cada una de ellas, hasta el punto de que en algunas de ellas las fases complejas son mayoritarias en relación con las demás fases e incluso en algún caso como el de Telletxea la estructura del hogar fue en todos los cortes censales o bien del tipo extenso o bien del tipo múltiple. Por ello, cabe destacar el hecho de que en algunos casos la complejidad familiar no era un estado pasajero ni una fase aislada del ciclo de vida, sino más bien una situación continua fundamentada en la corresidencia de parientes solteros, casados o viudos. Como es obvio, ese dato deja bien a las claras el arraigo de la familia troncal y de las formas complejas de familia entre los campesinos propietarios.

\section{CUADRO 7: ESTRUCTURA DE LOS HOGARES ENTRE 1824 Y 1894 EN LAS FAMILIAS RECONSTRUIDAS DEL CAMPESINADO PROPIETARIO.}

\begin{tabular}{|l|c|c|c|c|c|c|c|c|c|c|}
\cline { 2 - 10 } \multicolumn{1}{c|}{} & 1824 & 1832 & 1841 & 1850 & 1860 & 1867 & 1871 & 1880 & 1886 & 1894 \\
\hline OLARENEA & 5 & 5 & 3 & 3 & 3 & 3 & - & - & - & - \\
TELLETXEA & 5 & 4 & 4 & 4 & 4 & 4 & 4 & 4 & 4 & 5 \\
LANDAKOETXEA & 3 & 5 & 3 & 4 & 4 & 4 & 4 & 5 & 4 & 4 \\
ALDATEGIA & - & - & - & 3 & 3 & 3 & 3 & 3 & 5 & 4 \\
BERTIZBAITA & 5 & 5 & 3 & 5 & 5 & 5 & 5 & 3 & 3 & - \\
PERITXENEA & 3 & 5 & 5 & 4 & 4 & 3 & 4 & 5 & 4 & 3 \\
ITURRIA & 4 & 3 & 5 & 5 & 5 & 3 & 3 & 5 & 5 & 5 \\
ETXEBERRIA & 5 & 4 & 3 & 1 & 1 & 1 & - & - & - & - \\
ERROTALDEA & 3 & 3 & 3 & 3 & 3 & 2 & 3 & 3 & 3 & 3 \\
MIKELPERITZENEA & 3 & 3 & 5 & 5 & 3 & 3 & 3 & 5 & 3 & 3 \\
MADALENBAITA & 5 & 5 & 5 & 4 & 4 & 4 & 4 & 4 & 4 & 3 \\
GARTZIENEA & 5 & 5 & 3 & 5 & 3 & 4 & 3 & 3 & 3 & 5 \\
ERRANDONEA & 4 & 4 & 3 & 5 & 3 & 3 & 5 & 5 & 5 & 3 \\
GARAIKOETXEA & 5 & 3 & 5 & 3 & 3 & 2 & 3 & 3 & 1 & 3 \\
MARTIÑENEA & 4 & 4 & 4 & 4 & 4 & 5 & 3 & 3 & 3 & 4 \\
MATXIENEA & 5 & 5 & 5 & 4 & 3 & 3 & 3 & 5 & 5 & 5 \\
BORDA-A. & 5 & 5 & 5 & 5 & 5 & 5 & 3 & 5 & 5 & 2 \\
\hline
\end{tabular}

FUENTE: CENSOS DE LAS DISTINTAS FECHAS. ARCHIVO MUNICIPAL DE LESACA. ELABORACIÓN PROPIA.

Asimismo, en la mayoría de los casos se detectan alternancias entre momentos de estructura nuclear y momentos de estructura extensa o múltiple. Solamente en cuatro familias (las que eran dueñas de los patrimonios a cuya cabeza estaban los siguientes cuatro caseríos: Etxeberria de Zalain, Errotaldea, Garaikoetxea y Borda de Alcayaga) se advierten momentos en que las familias pasaron por fases de hogar solitario o sin estructura a causa del estado de viudedad de personas sin hijos o de la corresidencia de hermanos solteros o de tíos y sobrinos también solteros. 
CUADRO 8: ESTRUCTURA DE LOS HOGARES ENTRE 1824 Y 1894 EN LAS FAMILIAS RECONSTRUIDAS DEL CAMPESINADO ARRENDATARIO.

\begin{tabular}{|l|c|c|c|c|c|c|c|c|c|c|}
\cline { 2 - 10 } \multicolumn{1}{c|}{} & 1824 & 1832 & 1841 & 1850 & 1860 & 1867 & 1871 & 1880 & 1886 & 1894 \\
\hline BARRENETXEA-Z & 3 & 3 & 3 & 3 & 3 & 3 & 3 & 3 & 3 & 3 \\
BORDATX-MARTIN & 3 & 5 & 5 & 3 & 3 & 5 & 5 & 3 & 3 & 5 \\
BORDA-Z & 3 & 5 & 5 & 5 & 4 & 4 & 5 & 5 & 3 & 3 \\
GARAIK-MARISK & 5 & 3 & 3 & - & 3 & 5 & 4 & 4 & 4 & 5 \\
BEREK-OLARENEA & 3 & 5 & 3 & 3 & 3 & 3 & 3 & 5 & - & - \\
BARRENETXEA-Z & 5 & 3 & 3 & 3 & 3 & 3 & - & - & - & - \\
SOROA & - & 3 & 3 & 3 & 5 & - & - & - & - & - \\
BARRENETXEA-Z & - & - & - & 3 & 4 & 3 & 3 & 2 & 2 & 2 \\
BARREN-A-IPAR & - & - & - & 3 & 3 & 3 & 3 & 3 & 5 & 5 \\
ETXEB-MAJIN & - & - & - & 3 & 3 & 3 & 3 & 3 & 5 & 5 \\
BARRENETXEA-A & - & - & - & 3 & 3 & 3 & 3 & 3 & 5 & 5 \\
\hline
\end{tabular}

FUENTE: CENSOS DE LAS DISTINTAS FECHAS. ARCHIVO MUNICIPAL DE LESACA. ELABORACIÓN PROPIA.

En relación con las familias arrendatarias en el Cuadro 8 constan las diferentes estructuras de los once casos estudiados durante diversas fechas del periodo 1824-1894. De los once ejemplos, en diez se advierte la existencia de momentos en que la familia presenta soluciones complejas a lo largo de su trayectoria local. De esos diez en tres (los de Bordatxarrea-Martiñenea, Borda de Alcayaga y Garaikoetxea-Mariskonea) el hogar extenso o múltiple en la mitad o más de los cortes censales. En otros cuatro casos (los de Berekoetxea-Olarenea, Barrenetxea de Alcayaga-Iparragirrea, Etxeberrikoborda-Majirenarenborda y Barrenetxea de Alcayaga) en dos fechas se constata la presencia de multiplicidad, conviviendo dos núcleos conyugales de diferente nivel generacional unidos por vínculos de filiación). Llama la atención el hecho de que en los tres últimos ejemplos mencionados tanto en 1886 como en 1894 del hogar nuclear existente con anterioridad se pase a hogar múltiple. Asimismo, si nos fijamos en el número de hogares complejos sobre el total de hogares de familias arrendatarias en cada corte censal, concluiremos que sobre la muestra estudiada hacia el final del periodo se incrementó notablemente la proporción de las soluciones complejas en ese tipo de familias. Por lo tanto, de todo ello cabe pensar que también entre los arrendatarios, por las razones que sean, la complejidad familiar se daba con mayor frecuencia de lo que pudiera pensarse inicialmente. 


\section{El tamaño y la COMPOSICIÓN DE LOS HOGARES}

\subsection{El tamaño y la composición de los hogares. Un análisis estático}

Analizada ya la estructura, pasemos ahora a profundizar en la cuestión de las dimensiones y los componentes de los hogares de los barrios de Alcayaga y Zalain.

En el Cuadro 9 constan el número medio de personas totales por hogar, así como las cifras medias de hijos, parientes y sirvientes corresidentes. Según se advierte, las dimensiones medias de las unidades familiares de los barrios de Alcayaga y Zalain oscilaron entre el mínimo de 5,04 miembros de 1867 y el máximo de 6,67 de 1894, si bien en la mayoría de los cortes censales fluctuaron en una banda mucho más estrecha, entre las 5,30 y las 5,89 personas más exactamente. Evolutivamente se constata un descenso desde los relativamente elevados niveles de 1824 y 1832 hasta los menores de 1850 y 1867, comprobándose que la cifra de 1860 se coloca a medio camino entre aquéllas y éstas. Después de 1867 , se detecta un tímido ascenso en 1871 y 1880 que prosigue en 1886 cuando se alcanzan los 5,63 miembros. En la última fecha el crecimiento es muy notable puesto que las 6,67 personas de 1894 suponen una persona más en relación con el tamaño calculado para ocho años antes. Como veremos, esa elevada cifra de 1894 era ocasionada por la elevación del número de hijos que se advierte a partir de 1860 , pero sobre todo por el incremento de la cifra de parientes corresidentes que se observa a partir de 1880 y que alcanza su máximo precisamente en el último corte censal. Esos aumentos en las cifras de hijos y parientes pueden asociarse con los efectos sobre la oferta de trabajo relacionada con el sustancial incremento de la actividad de la fábrica de Vera desde principios de los años ochenta.

Hay que señalar que estas cifras son bastante similares a la media de personas que habitaba en la zona de caseríos del vecino pueblo de Vera en 1786 y que era de 5,64, siendo bastante superiores a la cifra media del conjunto de esa localidad que, lastradas por el tamaño medio de 3,91 personas de los hogares del casco urbano, equivalían a 4,45 personas. También las dimensiones de los caseríos de los dos barrios que estamos analizando son hondamente parecidas a las de los caseríos veratarras en 1857 que eran de 5,77 miembros ${ }^{25}$.

Por otra parte, centrándonos en los componentes de los grupos domésticos de Alcayaga y Zalain, se aprecia en el mismo Cuadro 9 que el número medio de hijos fue superior a partir de 1860 que antes de esa fecha. En 1824, 1832, 1841 y 1850 fluctuó levemente entre 1824 y 1850 entre un valor mínimo de 2,55 y otro máximo de 2,79. En 1860-1894 la cifra media de hijos se situó, con la sola excepción de la cifra de 1880 similar a la del periodo anterior. entre los 2,88 y $\operatorname{los} 2,98$.

25 Erdozain, Pilar y Mikelarena, Fernando, «Familia y hogar ...», p. 60.

Hispania, LXIII/1, núm. 213 (2003) 199-230 
CUADRO 9: TAMAÑO Y COMPOSICIÓN DEL HOGAR EN ALCAYAGA Y ZALAIN ENTRE 1824 Y 1860

\begin{tabular}{|c|c|c|c|c|}
\cline { 2 - 5 } \multicolumn{1}{c|}{} & TAMANO & HIJOS & PARIENTES & DOMÉSTICOS \\
\hline 1824 & 5,81 & 2,66 & 0,87 & 0,13 \\
1832 & 5,89 & 2,79 & 1,00 & 0,10 \\
1841 & 5,34 & 2,64 & 0,68 & 0,02 \\
1850 & 5,18 & 2,55 & 0,53 & 0,22 \\
1860 & 5,50 & 2,98 & 0,40 & 0,31 \\
1867 & 5,04 & 2,98 & 0,27 & 0,09 \\
1871 & 5,30 & 2,95 & 0,37 & 0,12 \\
1880 & 5,30 & 2,52 & 0,85 & 0,00 \\
1886 & 5,63 & 2,88 & 0,93 & 0,05 \\
1894 & 6,67 & 2,95 & 1,62 & 0,12 \\
\hline
\end{tabular}

FUENTE: CENSOS DE LAS DISTINTAS FECHAS. ARCHIVO MUNICIPAL DE LESACA. ELABORACIÓN PROPIA.

Por su parte, las cifras medias de parientes corresidentes registran una evolución que guarda similitudes a la de la complejidad familiar, descendiendo desde unos relativamente altos niveles en las dos fechas iniciales hasta unos valores medios en 1880 y apreciándose un notable aumento a partir de esa fecha, llegándose en 1880 y 1886 hasta niveles similares a las de las dos primeras fechas y alcanzándose en 1894 la elevadísima cifra de 1,62 parientes en cada hogar por término medio.

Por último, en relación con los sirvientes, en todos los cortes censales, con la sola excepción de 1850 y 1860 en donde se llega a los 0,2 ó 0,3, tienen una presencia residual.

\section{CUADRO 10: TAMAÑO Y COMPOSICIÓN DEL HOGAR DE LOS PROPIETARIOS Y DE LOS ARRENDATARIOS EN ALCAYAGA Y ZALAIN EN 1860.}

\begin{tabular}{|l|c|c|c|c|}
\cline { 2 - 5 } \multicolumn{1}{c|}{} & TAMAÑO & HIJOS & PARIENTES & DOMÉSTICOS \\
\hline PROPIETARIOS & 5,50 & 2,55 & 0,67 & 0,56 \\
ARRENDATARIOS & 5,50 & 3,29 & 0,21 & 0,12 \\
\hline
\end{tabular}

FUENTE: CENSOS DE LAS DISTINTAS FECHAS. ARCHIVO MUNICIPAL DE LESACA. ELABORACIÓN PROPIA.

De otro lado, el Cuadro 10 nos permite calibrar el peso de los factores socioeconómicos sobre el tamaño y la presencia de los diversos componentes en los grupos domésticos de los barrios estudiados. De los datos ahí presentados llama la atención que propietarios y renteros contaran con las mismas dimen- 
siones medias y que el número medio de hijos de los segundos fuera bastante superior al de los primeros. Esto último es ciertamente chocante porque lo inicialmente esperable era que los propietarios poseyeran una mayor capacidad de retención de los hijos en el propio hogar. Los datos concernientes a parientes y a domésticos, en cambio, son más lógicos. Su número era considerablemente menor entre los arrendatarios, en un caso por efecto de su menor complejidad familiar y en el otro por efecto de sus menores recursos económicos.

\subsection{El tamaño de los hogares. Un análisis dinámico.}

También hemos analizado las dimensiones de los hogares desde una perspectiva dinámica a partir de los 28 casos de familias presentes en todos los cortes censales. La hipótesis a verificar era la de si en cada una de ellas se advierten disimilitudes de importancia en cuanto a su tamaño a lo largo de su ciclo de vida.

\section{CUADRO 11: TAMAÑO DE LOS HOGARES ENTRE 1824 Y 1894 EN LAS FAMILIAS RECONSTRUIDAS DE CAMPESINOS PROPIETARIOS.}

\begin{tabular}{|l|c|c|c|c|c|c|c|c|c|c|}
\cline { 2 - 11 } \multicolumn{1}{c|}{} & 1824 & 1832 & 1841 & 1850 & 1860 & 1867 & 1871 & 1880 & 1886 & 1894 \\
\hline OLARENEA & 9 & 11 & 12 & 5 & 2 & 2 & - & - & - & - \\
TELLETXEA & 9 & 12 & 9 & 7 & 8 & 5 & 11 & 13 & 13 & 9 \\
LANDAKOETXEA & 5 & 9 & 6 & 9 & 6 & 8 & 7 & 6 & 9 & 7 \\
ALDATEGIA & - & - & - & 5 & 8 & 8 & 8 & 7 & 7 & 4 \\
BERTIZBAITA & 7 & 7 & 5 & 5 & 7 & 11 & 12 & 7 & 5 & - \\
PERITXENEA & 9 & 7 & 9 & 9 & 9 & 7 & 7 & 4 & 8 & 6 \\
ITURRIA & 8 & 7 & 10 & 12 & 13 & 7 & 7 & 6 & 8 & 10 \\
ETXEBERRIA & 6 & 3 & 2 & 2 & 2 & 2 & - & - & - & - \\
ERROTALDEA & 6 & 4 & 3 & 5 & 4 & 2 & 5 & 5 & 6 & 5 \\
MIKELPERITZENEA & 5 & 5 & 5 & 4 & 2 & 2 & 4 & 4 & 6 & 9 \\
MADALENBAITA & 6 & 6 & 6 & 5 & 6 & 7 & 9 & 9 & 9 & 8 \\
GARTZIENEA & 6 & 8 & 9 & 10 & 2 & 3 & 3 & 2 & 2 & 6 \\
ERRANDONEA & 6 & 6 & 5 & 8 & 5 & 5 & 6 & 6 & 5 & 4 \\
GARAIKOETXEA & 8 & 7 & 7 & 7 & 3 & 2 & 2 & 2 & 2 & 8 \\
MARTINNENEA & 9 & 8 & 8 & 5 & 4 & 7 & 8 & 11 & 8 & 10 \\
MATXIENEA & 10 & 8 & 6 & 6 & 5 & 5 & 3 & 3 & 3 & 3 \\
BORDA-A. & 3 & 4 & 3 & 4 & 5 & 4 & 2 & 3 & 3 & 2 \\
\hline
\end{tabular}

FUENTE: CENSOS DE LAS DISTINTAS FECHAS. ARCHIVO MUNICIPAL DE LESACA. ELABORACIÓN PROPIA.

Según se comprueba en el Cuadro 11 referido a las familias de los campesinos propietarios hay algunos pocos casos en los que el hogar contó siempre con un número bastante similar de miembros. Con todo, son mayoría los casos en

Hispania, LXIII/1, núm. 213 (2003) 199-230 
los que hay diferencias de importancia, habiendo fechas en los que el hogar cuenta con un relativamente alto número de componentes y otras en los que ese número es bastante más bajo. Lo mismo ocurría, tal y como se ve en el siguiente Cuadro 12, con las familias de los campesinos arrendatarios.

CUADRO 12: TAMAÑO DE LOS HOGARES ENTRE 1824 Y 1894 EN LAS FAMILIAS RECONSTRUIDAS DE CAMPESINOS ARRENDATARIOS.

\begin{tabular}{|l|c|c|c|c|c|c|c|c|c|c|}
\cline { 2 - 9 } \multicolumn{1}{c|}{} & 1824 & 1832 & 1841 & 1850 & 1860 & 1867 & 1871 & 1880 & 1886 & 1894 \\
\hline BARRENETXEA-Z & 7 & 5 & 2 & 5 & 6 & 6 & 4 & 3 & 3 & 3 \\
BORDATX-MARTIN & 5 & 6 & 6 & 6 & 6 & 6 & 5 & 6 & 6 & 7 \\
BORDA-Z & 6 & 6 & 5 & 5 & 5 & 3 & 6 & 5 & 3 & 3 \\
GARAIK-MARISK & 5 & 6 & 5 & - & 5 & 5 & 5 & 5 & 5 & 9 \\
BEREK-OLARENEA & 2 & 5 & 7 & 7 & 7 & 5 & 5 & 6 & - & - \\
BARRENETXEA-Z & 3 & 2 & 2 & 2 & 2 & 2 & - & - & - & - \\
SOROA & - & 3 & 3 & 3 & 6 & - & - & - & - & - \\
BARRENETXEA-Z & - & - & - & 6 & 5 & 5 & 5 & 3 & 3 & 2 \\
BARREN-A-IPAR & - & - & - & 6 & 7 & 7 & 5 & 4 & 5 & 8 \\
ETXEB-MAJIN & - & - & - & 4 & 8 & 7 & 5 & 3 & 11 & 11 \\
BARRENETXEA-A & - & - & - & 5 & 6 & 7 & 7 & 7 & 6 & 6 \\
\hline
\end{tabular}

FUENTE: CENSOS DE LAS DISTINTAS FECHAS. ARCHIVO MUNICIPAL DE LESACA. ELABORACIÓN PROPIA.

\section{UNIDADES DE TRABAJO Y UNIDADES DE CONSUMO EN LOS HOGARES DE AlCAYAga Y Zalain.}

La pregunta que nos planteamos en este apartado es si los hogares de los campesinos propietarios, fundamentados en las pautas propias de la familia troncal, conseguían, por medio de la presencia de parientes corresidentes, dando lugar a soluciones de complejidad familiar, mantener una relación equilibrada entre miembros consumidores y miembros productores. De hecho, hace una decena de años, Mikelarena ${ }^{26}$ comparó el volumen de fuerza de trabajo y la relación entre mano de obra y consumidores de las unidades familiares de 29 partidos judiciales de España caracterizados por la familia troncal con los de otros 20 partidos judiciales descritos como predominantemente nucleares. Según se apreciaba, las familias medias de los partidos judiciales troncales arrojaban un número medio más elevado de miembros productivos que las de los partidos nucleares ${ }^{27}$. Asimismo, se apuntaba que en el caso de los hogares fundamentados

\footnotetext{
26 MikelarenA, F., «Las estructuras familiares...., pp. 49-57.

27 Hay que tener en cuenta que el modelo planteado por Reher y Camps y sobre la relación entre producción y consumo en los hogares conquenses, fundamentados en la familia nuclear, afir-
} 
en pautas troncales de formación de la familia, el aumento de los consumidores netos que tenía lugar cuando crecía el número de los hijos pequeños del matrimonio joven que heredaba la casa podía ser amortiguado por la colaboración de los hijos desheredados de la misma generación que el heredero. De esta forma, los hermanos solteros de quien recibía la transmisión indivisa del patrimonio podrían cubrir eficazmente el periodo de transición hasta que los hijos de éste llegaran a la edad de hacer frente al trabajo en la casa, pudiendo incluso permanecer después, como mano de obra intrafamiliar complementaria.

Bajo todo ello, parecería plausible que la presencia de hogares extensos y complejos en Alcayaga y Zalain durante todo el periodo 1824-1894, especialmente entre el campesinado propietario, diera lugar a cocientes repetidamente positivos entre unos miembros y otros. Para validar esa hipótesis hemos calculado las cifras de cada uno de esos dos tipos de miembros del hogar y hemos calculado la relación para cada familia en cada fecha censal.

El cálculo de las unidades de consumo se ha obtenido mediante la aplicación de unos coeficientes de consumo standard por grupos de edad y sexo, baremos que fueron propugnados por Mueller $^{28}$ y que han sido utilizados por diversos autores ${ }^{29}$.

En relación a la medición de las unidades de trabajo hemos considerado como población activa aquélla cuyas edades quedaban comprendidas entre los 15 y los 64 años. Los coeficientes de trabajo por edad y sexo son los siguientes: 0,5 para los varones con edades entre los 15 y los 19 años, 1 para los varones entre 20 y 64 años y 0,5 para las mujeres con edades entre los 15 y los 64 años.

\footnotetext{
ma la siguiente evolución a lo largo de la trayectoria vital del grupo doméstico: a) en los primeros años de los matrimonios el saldo era netamente positivo: al llegar a los 30 años, el número medio de hijos de las parejas era inferior a 1,5 y por tanto los hogares, con pocos consumidores todavía, gozaban de un superávit económico; b) entre los 30 y 39 años el balance era bastante negativo, en cuanto que las parejas contaban con más hijos y aún ninguno de ellos había llegado a una edad plenamente productiva; c) entre los 40 y los 49 años el saldo mejoraba, aunque no llegaba a ser muy positivo porque predominaban los hijos con más de 10 años, que ya podían compensar su consumo con la aportación de ingresos a la economía doméstica; d) entre los 50 y los 59 años la situación era claramente favorable en cuanto que los hijos que permanecían residiendo en la casa paterna eran ya adultos y, por consiguiente, productores netos; e) de los 60 años en adelante, en cambio, los padres ancianos eran sólo consumidores, con una capacidad productiva muy mermada. REHER, D.S., Familia, población y sociedad en la provincia de Cuenca, 1700-1970, Madrid, 1988, pp. 192-194 y CAMPS, E. y REHER, D.S., «Las economías familiares dentro de un contexto histórico comparado», Revista Española de Investigaciones Sociológicas, 55, 1991, 65-91.

28 MUELler, Eva, «The economic value of children in peasant agriculture», en RIDKER, Ronald G. (ed.), Population and Development. The search for selective interventions, Baltimore, 1976, pp. 98-152.

29 Los coeficientes de consumo son los siguientes: 0,32 para los varones con edades comprendidas entre los 0 y 4 años, 0,52 para los varones entre 5 y 9 años, 0,82 para los varones entre 10 y 14 años, 1 para los varones entre 15 y 54 años, 0,9 para los varones entre 55 y 59 años, 0,8 para los varones entre 60 y 64 años y 0,7 para los varones con 65 años en adelante; para las mujeres, 0,32 para el intervalo de 0 a 4 años, 0,48 para el de 5 a 9 años, 0,68 para el de 10 a 14 años, 0,8 para el de 15 a 54 años, 0,72 para el de 55 a 59 años, 0,64 para el de 60 a 64 años y 0,56 para las de 65 años en adelante.
} 
CUADRO 13: ZALAIN Y ALCAYAGA 1824-1894. EVOLUCIÓN DEL COCIENTE ENTRE UNIDADES DE TRABAJO Y UNIDADES DE CONSUMO EN LOS CASERÍOS DE PROPIETARIOS E INQUILINOS.

\begin{tabular}{|c|c|c|c|c|c|c|c|c|c|c|}
\hline & 1824 & 1832 & 1841 & 1850 & 1860 & 1867 & 1871 & 1880 & 1886 & 1894 \\
\hline \multicolumn{11}{|l|}{ PROPIETARIOS } \\
\hline PERITXENEA & 0,7 & 0,9 & 0,6 & 0,5 & 0,8 & 0,8 & 0,9 & 0,5 & 0,5 & 0,3 \\
\hline ITURRIA & 0,5 & 0,6 & 0,7 & 0,4 & 0,6 & 0,7 & 0,7 & 0,3 & 0,5 & 0,5 \\
\hline ETXEBERRIA & 0,6 & 0,9 & 1,0 & 0,6 & 0,3 & 0,6 & n.d. & n.d. & n.d. & n.d. \\
\hline ERROTALDEA & 0,9 & 0,5 & 0,7 & 0,5 & 0,7 & 1,0 & 0,7 & 0,5 & 0,4 & 0,7 \\
\hline MADALENBAITA & 0,6 & 0,5 & 0,5 & 0,8 & 0,6 & 0,5 & 0,4 & 0,6 & 0,6 & 0,7 \\
\hline MIKELLPERITZENEA & 0,5 & 0,7 & 0,7 & 0,7 & 1,0 & 0,0 & 0,5 & 0,5 & 0,4 & 0,3 \\
\hline OLARENEA & 0,3 & 0,2 & 0,4 & 0,5 & 1,0 & 0,0 & n.d. & n.d. & n.d. & n.d. \\
\hline TELLETXEA & 0,6 & 0,5 & 0,8 & 0,8 & 0,8 & 0,9 & 0,7 & 0,6 & 0,7 & 0,7 \\
\hline LANDAKOTXEA & 0,7 & 0,6 & 0,4 & 0,5 & 0,6 & 1,1 & 0,5 & 0,7 & 0,6 & 0,5 \\
\hline BERTIZBAITA & 0,4 & 0,2 & 0,8 & 0,8 & 0,3 & 0,3 & 0,4 & 0,5 & 0,7 & n.d. \\
\hline MARTIÑNENEA & 0,5 & 0,6 & 0,7 & 0,6 & 0,6 & 0,3 & 0,4 & 0,4 & 0,5 & 0,6 \\
\hline MATXIENEA & 0,5 & 0,4 & 0,8 & 0,6 & 0,6 & 0,8 & 0,9 & 1,0 & 0,6 & n.d. \\
\hline BORDA ALCAYAGA & 0,8 & 0,5 & 0,7 & 0,5 & 0,4 & 0,3 & 0,4 & 0,5 & 0,4 & 0,3 \\
\hline GARTZIENEA & 0,6 & 0,4 & 0,4 & 0,7 & 0,8 & 0,9 & 0,8 & 0,9 & 0,3 & 0,4 \\
\hline ERRANDONEA & 0,6 & 0,7 & 0,9 & 0,3 & 0,5 & 0,8 & 0,8 & 0,6 & 0,3 & 0,8 \\
\hline GARAIKOTXEA & 0,4 & 0,4 & 0,5 & 0,8 & 0,6 & 0,8 & 0,8 & 0,9 & 0,8 & 0,4 \\
\hline ALDATEGIA & n.d. & n.d. & n.d. & 0,5 & 0,3 & 0,6 & 0,7 & 0,8 & 0,7 & 0,8 \\
\hline \multicolumn{11}{|l|}{ INQUILINOS } \\
\hline BORDA-Z & 0,9 & 0,9 & 0,6 & 0,8 & 0,8 & 0,7 & 0,4 & 0,4 & 0,4 & 0,6 \\
\hline BEREKOETXEA & 1,1 & 0,8 & 0,3 & 0,4 & 0,8 & 0,5 & 0,5 & 0,4 & n.d. & n.d. \\
\hline BARRENETXEA ZA. & 0,6 & 0,8 & 0,9 & 0,7 & 0,0 & 0,0 & n.d. & n.d. & n.d. & n.d. \\
\hline BARRENETXEA ZA. & 0,7 & 0,8 & 0,8 & 0,5 & 0,5 & 0,7 & 0,9 & 0,8 & 0,8 & 0,7 \\
\hline BORDATXARREA & 0,8 & 0,8 & 0,4 & 0,5 & 0,8 & 0,5 & 0,4 & 0,4 & 0,5 & 0,9 \\
\hline MARISKONIA & 0,4 & 0,4 & 0,6 & n.d. & 0,5 & 0,7 & 0,7 & 0,6 & 0,9 & 0,7 \\
\hline BARRENETXEA ZA. & n.d. & n.d. & n.d. & 0,5 & 0,8 & 0,6 & 0,6 & 0,9 & 0,9 & 1,0 \\
\hline IPARRAGIRREA & n.d. & n.d. & n.d. & 0,5 & 0,3 & 0,6 & 0,7 & 0,9 & 0,5 & 0,3 \\
\hline ETXEBERRIKOBORD & n.d. & n.d. & n.d. & 0,6 & 0,3 & 0,5 & 0,6 & 0,8 & 0,5 & 0,3 \\
\hline BARRENETXEA AL. & n.d: & n.d. & n.d. & 0,5 & 0,4 & 0,5 & 0,3 & 0,7 & 0,9 & 0,7 \\
\hline
\end{tabular}

FUENTE: CENSOS DE POBLACIÓN DE LAS FECHAS RESPECTIVAS. ELABORACIÓN PROPIA.

Los cocientes de relación entre unos miembros del hogar y otros aparece reflejada en el Cuadro 13. En relación con el campesinado propietario, la conclusión primordial que puede inferirse de él es lo incierto de la afirmación de que la familia troncal entre ese sector social, básicamente por la posibilidad de disposición de mano de obra complementaria que ofrecían los parientes solteros, quede caracterizada por unas relaciones equilibradas persistentes en el tiempo entre 
miembros productores y miembros consumidores. A pesar de que en algunos casos (como los de Peritxenea, Errotaldea, Telletxea, Gartzienea, Garaikoetxea) se han estimado cocientes de 0,7 o superiores para cinco o más fechas de los diez cortes censales, en los demás casos sólo excepcionalmente se llega a niveles altos. Además, en todas las familias, con la sola salvedad de la de Telletxea, se presentan cocientes de 0,4 ó inferiores, en algunos casos durante varios cortes censales, destacando Olarenea, Bertizbaita, Borda de Alcayaga y Gartzienea por lo repetido en ellos de los bajos cocientes. En relación con el campesinado arrendatario, llama la atención el hecho de que en ese sector los cocientes positivos tengan, más o menos, una presencia similar a la que tenían entre los campesinos propietarios, siendo en éstos mucho más habituales las soluciones de complejidad familiar. Esto se puede entender en el sentido de que las familias estrictamente troncales de los campesinos propietarios no tenían de por sí una capacidad de respuesta superior a las de los arrendatarios, éstas solo eventualmente complejas, en relación a la adecuación de la mano de obra al número de consumidores. Por otra parte, aún cuando los cocientes elevados tengan una significación real limitada por cuanto desconocemos la aplicación laboral real o el nivel de captación de ingresos de la fuerza de trabajo potencial contabilizada, resulta evidente que en los casos de mayor desfase entre productores y consumidores la pobreza se presentaría con mayor virulencia.

\section{CONCLUSIONES}

El análisis efectuado a partir del seguimiento a lo largo del tiempo de 28 familias muestra lo arraigado de la familia troncal entre los campesinos propietarios de la Vasconia holohúmeda. En el caso de los campesinos arrendatarios, se constata que las formas complejas del hogar no eran tan excepcionales como inicialmente podía pensarse, si bien eran mucho menos habituales que entre los campesinos propietarios. La diferente composición interna de los hogares de unos y de otros, sin embargo, no se trasladaba con absoluta claridad al ámbito de la relación entre productores y consumidores. A pesar de poder contar con el recurso de los parientes como mano de obra complementaria, los campesinos propietarios no revelan unos cocientes productores-consumidores más satisfactorios que los que se estiman para los arrendatarios. 